\title{
Practical added resistance diagrams to predict fouling impact on ship performance
}

\author{
Yigit Kemal Demirel*, Soonseok Song, Osman Turan, Atilla Incecik \\ Department of Naval Architecture, Ocean and Marine Engineering, University of Strathclyde, \\ 100 Montrose Street, Glasgow, G4 0LZ, United Kingdom \\ *corresponding author; e-mail: yigit.demirel@strath.ac.uk, phone: +44(0)1415483463
}

\begin{abstract}
The main aim of this paper is to generate added resistance diagrams to be used for the prediction of the increases in the frictional resistance coefficients and effective powers of ships due to the use of a range of coating and biofouling conditions. For this reason, an in-house code was developed based on the boundary layer similarity law analysis.

Roughness effects of a range of representative coating and fouling conditions on the frictional resistances of flat plates across a large number of ship lengths were then predicted. Hence, an extensive database of added frictional resistance coefficients was evaluated for varying ship lengths, ship speeds and fouling conditions. The added resistance diagrams were then presented from $10 \mathrm{~m}$ to $400 \mathrm{~m}$ ship lengths and from slow to high ship speeds for each surface condition. Added resistances and powering penalties of different types of ships including DTMB 5415, $\mathrm{KCS}, \mathrm{JBC}$ and KVLCC2 were predicted using the generated diagrams.
\end{abstract}

Keywords: Hull Roughness and Biofouling, Added Resistance Diagrams, Ship Resistance and Powering

\section{INTRODUCTION}

Roughness of a ship's hull, which is often caused by marine coatings and biofouling, can dramatically increase a ship's frictional resistance and hence its fuel consumption and greenhouse gas emissions. Due to its detrimental effects on ship efficiency and the marine ecosystem, it is desirable to mitigate the accumulation of biofouling on ship hulls. Marine coatings are prevalently used to keep hull surfaces clean and if applied with a proper cathodic protection system also prevents corrosion (Tezdogan and Demirel, 2014)

Although several existing studies have investigated the coating roughness and hull fouling effect on ship resistance and powering by conducting full-scale trials and measurements (Corbett et al., 2011; Munk, 2006), the results include many uncertainties due to different operational conditions, routes, human factors and so on, as can be seen from the literature.

Experimental, lab-scale studies, on the other hand, provide more reliable data since the uncertainties can be estimated to a degree. Therefore, several experimental studies have been devoted to investigating the roughness effect on skin friction. According to Schultz and Swain (2000), the increase in the frictional resistance of surfaces covered with slime was surveyed by conducting towing tests of flat plates by Benson et al. (1938), and by performing experiments on cylinders, rotating disks and a model ship by Watanabe et al. (1969). Lewkowicz and Das (1986) conducted towing tests of flat plates covered with artificial slime and the increase in the frictional resistance due to artificial slime was found to be $18 \%$ (Schultz and Swain, 2000). Loeb et al. (1984) conducted rotating disk experiments using disks covered with several different types of microbial slimes. It was observed that microbial slime led to an increase of 
$10 \%$ to $20 \%$ in the frictional resistance. Schultz and Swain (1999) investigated the effects of biofilms and algae on the skin friction coefficients of flat plates using boundary layer measurements. Swain et al. (2007) surveyed the fouling growth on different types of coatings under static and dynamic conditions. Andrewartha et al. (2010) measured an increase of 99\% in the drag coefficients of test plates due to biofilms in a recirculating water tunnel. Schultz et al. (2015) compared the frictional drag of test plates, in a fully turbulent flow channel, in smooth condition and after dynamic exposure to diatomaceous biofilms up to 6 months. They observed up to $70 \%$ increase in skin friction of the test plates due to biofilms. Recently, there have been studies using replicated fouling geometries, which are recreated through casting, 3D scanning and printing to investigate the effect of biofouling without introducing the real fouling into experimental facilities. Monty et al. (2016) scanned light calcareous tubeworm fouling, scaled and reproduced for wind-tunnel testing to determine the equivalent sand-grain roughness, $k_{s}$. Using the obtained equivalent sand-grain roughness, they predicted a $23 \%$ increase in the total resistance of a frigate due to the light calcareous fouling. Demirel et al. (2017a) conducted a series of towing test using flat plates covered with 3D printed artificial barnacle patches and observed a $119 \%$ increase in skin friction due to the barnacles of varying sizes and coverages. Gowing et al. (2018) measured the drag of 3D printed panels of barnacles, oysters and tubeworms of varying spatial density and size scales, and the levels of fouling conditions were converted to the equivalent sand-grain roughness. Womack et al. (2018) measured the boundary layer characteristics along with idealised model barnacles in shape of truncated cones, and they found the equivalent sand-grain roughness height and skin friction coefficients according to the densities of the model barnacles.

Although a large body of research has been devoted to assessing the effects of fouling on ship resistance and powering, little effort has been made to classify fouling conditions and relate them to full-scale ship frictional resistance.

A well-known similarity law scaling procedure of Granville (1958) can be used to predict the effect of roughness on the frictional resistance of flat plates of ship lengths, provided that the roughness function behaviour of such fouling is known (Schultz, 2007). This procedure can also be used for fouled surfaces. Some examples of the use of this method are given by Schultz (2002), Schultz (2004), Shapiro (2004), Schultz (2007), Flack and Schultz (2010), Schultz et al. (2011), Demirel et al. (2013), Demirel (2015), Turan et al. (2016), Demirel et al. (2017) and Song et al. (2019a). Schultz (2007) proposed a methodology to predict the effects of a range of coating and biofouling conditions on ship frictional resistance, using his experimental data, by means of the similarity law scaling procedure of Granville (1958).

Recently, with the rapid growth of computational power, the use of Computational Fluid Dynamics (CFD) is also considered as an effective method to predict the roughness effect on ship resistance (Atlar et al., 2019). Accordingly, there have been an increasing number of studies utilising CFD simulations to predict the effect of marine coatings and biofouling on ship resistance (Izaquirre-Alza et al., 2010; Demirel et al., 2014; Demirel et al., 2017b; Farkas et al., 2018; Song et al., 2019a), and on the propeller performance (Owen et al., 2018; Song et al., 2019b).

Although these studies clearly demonstrate the critical impact of surface fouling on ship performances, it may be difficult for less experienced users to carry out such an analysis using the aforementioned methodologies. Goal-based, simple added resistance diagrams to predict the effect of biofouling on ship frictional resistance would, therefore, be of great benefit.

To the best of the authors' knowledge, no specific added resistance diagram exists to predict the roughness effects of coatings and biofouling on ship frictional resistance. The aim of the present paper is, therefore, to fill this gap by generating such diagrams using an in-house code based on the similarity law scaling procedure explained by Schultz (2007), for an extensive range of ship lengths and ship speeds. This study may, therefore, be considered as an extension 
of the study presented in Schultz (2007). The proposed diagrams enable the prediction of the added frictional resistance coefficients due to a range of biofouling conditions for different ship lengths and speeds.

This paper is organised as follows: The similarity law scaling procedure is explained in detail in Section 2. In Section 3, an extensive database of added resistance coefficients is generated, and added resistance diagrams are plotted. In addition, powering predictions of ships are made using the generated diagrams. Finally, the results of the study are discussed in Section 4, along with recommendations for future avenues of research.

\section{METHODOLOGY}

\subsection{Granville's boundary layer similarity law scaling}

The prediction code was developed based on the similarity law scaling procedure proposed by Granville (1958), which is explained in detail by Schultz (1998, 2007). Using this extrapolation method, the effect of surface roughness on the frictional resistance of ships of arbitrary length can be predicted, provided that the roughness function of the given surface is known.

Figure 1 graphically illustrates Granville's similarity law scaling procedure. The first step of the procedure is plotting the frictional resistance coefficient of a flat plate, $\mathrm{C}_{\mathrm{Fsmooth}}$, against $\log$ (Re). In this study, the Kàrmàn-Schoenherr friction line (Schoenherr, 1932) was used for smooth friction lines, given as

$$
\frac{0.242}{\sqrt{C_{F}}}=\log \left(\operatorname{Re} \cdot C_{F}\right)
$$

where $\mathrm{Re}$ is the Reynolds number, $\mathrm{C}_{\mathrm{F}}$ is the frictional drag coefficient. The second step is to shift the $\mathrm{C}_{\mathrm{Fsmooth}}$ curve by $\Delta \mathrm{U}^{+} \kappa[\ln (10)]^{-1}$ in the $\log (\mathrm{Re})$ direction. This new curve is referred to as $\mathrm{C}_{\text {Frough. }}$ The third step is to plot the line of the constant $\mathrm{L}_{\text {plate }}+$ value, satisfying equation (2)

$$
\operatorname{Re}=\frac{L_{\text {plate }}^{+}}{\sqrt{\frac{C_{F}}{2}}\left(1-\frac{1}{\kappa} \sqrt{\frac{C_{F}}{2}}\right)}
$$

where $\kappa$ is the von Karman constant and $\mathrm{L}_{\text {plate }}+$ is non-dimensional plate length and can be defined by

$$
L_{\text {plate }}^{+}=\frac{L_{\text {plate }} U_{\tau}}{v}
$$

where $\mathrm{L}_{\text {plate }}$ is the plate length, $U_{\tau}$ is the friction velocity defined as $\sqrt{\tau_{w} / \rho}, v$ is the kinematic viscosity, $\tau_{w}$ is the shear stress magnitude and $\rho$ is the density of the fluid.

The fourth step is to shift the line of constant $\mathrm{L}_{\text {plate }}+$ a distance of $\log \left(\mathrm{L}_{\text {ship }} / \mathrm{L}_{\text {plate }}\right)$ in the $\log$ (Re) direction. This is then termed $\mathrm{L}_{\text {ship }}+$. The intersection of $\mathrm{L}_{\text {ship }}+$ and $\mathrm{C}_{\text {Frough }}$ gives the ship scale $\mathrm{C}_{\mathrm{F}}$ value. The difference between the evaluated $\mathrm{C}_{\text {Frough }}$ of the ship and the $\mathrm{C}_{\mathrm{Fsmooth}}$ of the ship (which can be calculated using equation (1) for the same Reynolds number gives the added resistance coefficient, $\Delta \mathrm{C}_{\mathrm{F}}$, of the ship due to roughness.

As seen from the above explanations, this procedure includes several numerical procedures which may cause numerical errors, should this be done manually for each case. An in-house numerical code, therefore, was developed in order to have a robust and fast solution. The inputs of the said code are roughness height, roughness functions and corresponding roughness 
Reynolds numbers and the desired ship lengths. The code then calculates $\mathrm{C}_{\mathrm{F}}$ values of ships for a given roughness on their hull for several ship speeds (depending on the number of $\Delta \mathrm{U}^{+}$and $\mathrm{k}^{+}$pairs).

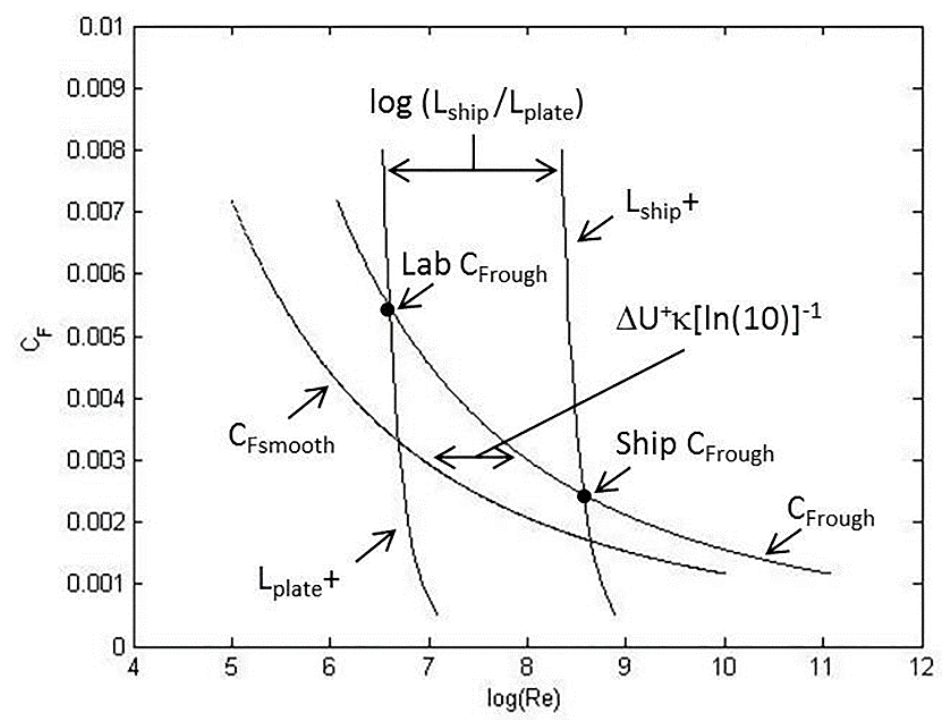

Figure 1: Graphical illustration of Granville's similarity law scaling

\subsection{Roughness Functions and Fouling Conditions}

Schultz and Flack (2007) determined the roughness functions for three dimensional rough surfaces similar to those used by Shockling et al. (2006). Schultz (2007) proposed that the roughness function behaviour of a range of fouling conditions follow the roughness functions of Schultz and Flack (2007) and Shockling et al. (2006), based on his previous work presented in Schultz (2004). This is a reasonable assumption since the roughness functions of real surfaces are expected to show behaviour that is between the monotonic Colebrook and inflectional Nikuradse type roughness functions, such as those presented by Schultz and Flack (2007) and Shockling et al. (2006), as shown in Figure 2.

In addition, Schultz (2007) presented the equivalent sand roughness heights for a range of coating and fouling conditions together with the NSTM (Naval Ships' Technical Manual) rating and average coating roughness $\left(\mathrm{Rt}_{50}\right)$ based on his extensive experiments including Schultz (2004) (Table 1). 


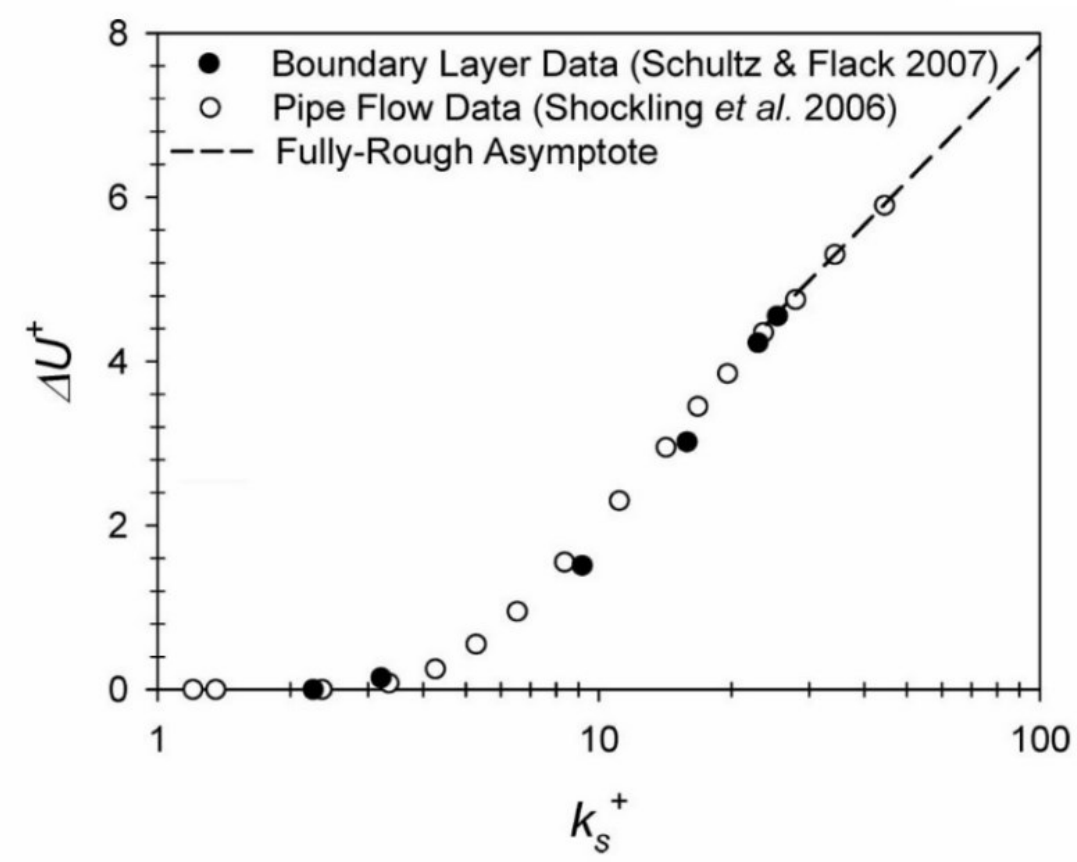

Figure 2: Roughness function vs roughness Reynolds numbers (Schultz, 2007).

Table 1: A range of representative coating and fouling conditions. (Schultz, 2007).

\begin{tabular}{lccc}
\hline \multicolumn{1}{c}{ Description of condition } & NSTM rating* & $\mathrm{k}_{\mathrm{s}}(\mu \mathrm{m})$ & $\mathrm{Rt}_{50}(\mu \mathrm{m})$ \\
\hline $\begin{array}{l}\text { Hydraulically smooth } \\
\text { surface }\end{array}$ & 0 & 0 & 0 \\
$\begin{array}{l}\text { Typical as applied AF } \\
\text { coating }\end{array}$ & 0 & 30 & 150 \\
$\begin{array}{l}\text { Deteriorated coating or light } \\
\text { slime }\end{array}$ & $10-20$ & 100 & 300 \\
$\begin{array}{l}\text { Heavy slime } \\
\text { Small calcareous fouling or }\end{array}$ & 30 & 300 & 600 \\
weed & $40-60$ & 1000 & 1000 \\
$\begin{array}{l}\text { Medium calcareous fouling } \\
\text { Heavy calcareous fouling }\end{array}$ & $70-80$ & 3000 & 3000 \\
*NSTM (2002) & $90-100$ & 10000 & 10000 \\
\hline
\end{tabular}

The present predictions were made based on the assumptions that the given fouling conditions can be represented by these roughness functions and roughness length scales. Schultz (2007) validated these assumptions and this method by comparing his results with other studies such as Hundley and Tate (1980) and Haslbeck and Bohlander (1992), documenting the effects of coatings and biofouling on ship powering through full-scale trials.

\section{PREDICTING THE ROUGHNESS EFFECTS OF BIOFOULING ON SHIP RESISTANCE AND POWERING}

\subsection{Added Resistance Diagrams}

The roughness functions and roughness Reynolds numbers given in the previous section were employed in the code and predictions were made for varying fouling conditions and ship speeds and for ship lengths from $10 \mathrm{~m}$ to $400 \mathrm{~m}$ with $10 \mathrm{~m}$ increments. The added resistance diagrams were then generated using this database. For visual and practical convenience, only six cases 
are presented in this section, and the added resistance diagrams including all ship lengths can be found in Appendix (Figure A.1-A.24).

The added resistance diagrams for flat plates representing a $20 \mathrm{~m}$ yacht, a $60 \mathrm{~m}$ research vessel, a 140m navy surface combatant (DTMB 5415), a 230m containership (KCS), a 280m bulk carrier (JBC) and a 320m tanker (KVLCC2) are presented and discussed in this section. The added resistance coefficients, $\Delta \mathrm{C}_{\mathrm{F}}$, due to a typical coating and different fouling conditions, were plotted against the ship speeds. The diagrams are given separately for each surface condition. These diagrams (Figure 3 - Figure 8) can be used directly to predict the added resistance of the ships under the given fouling conditions.

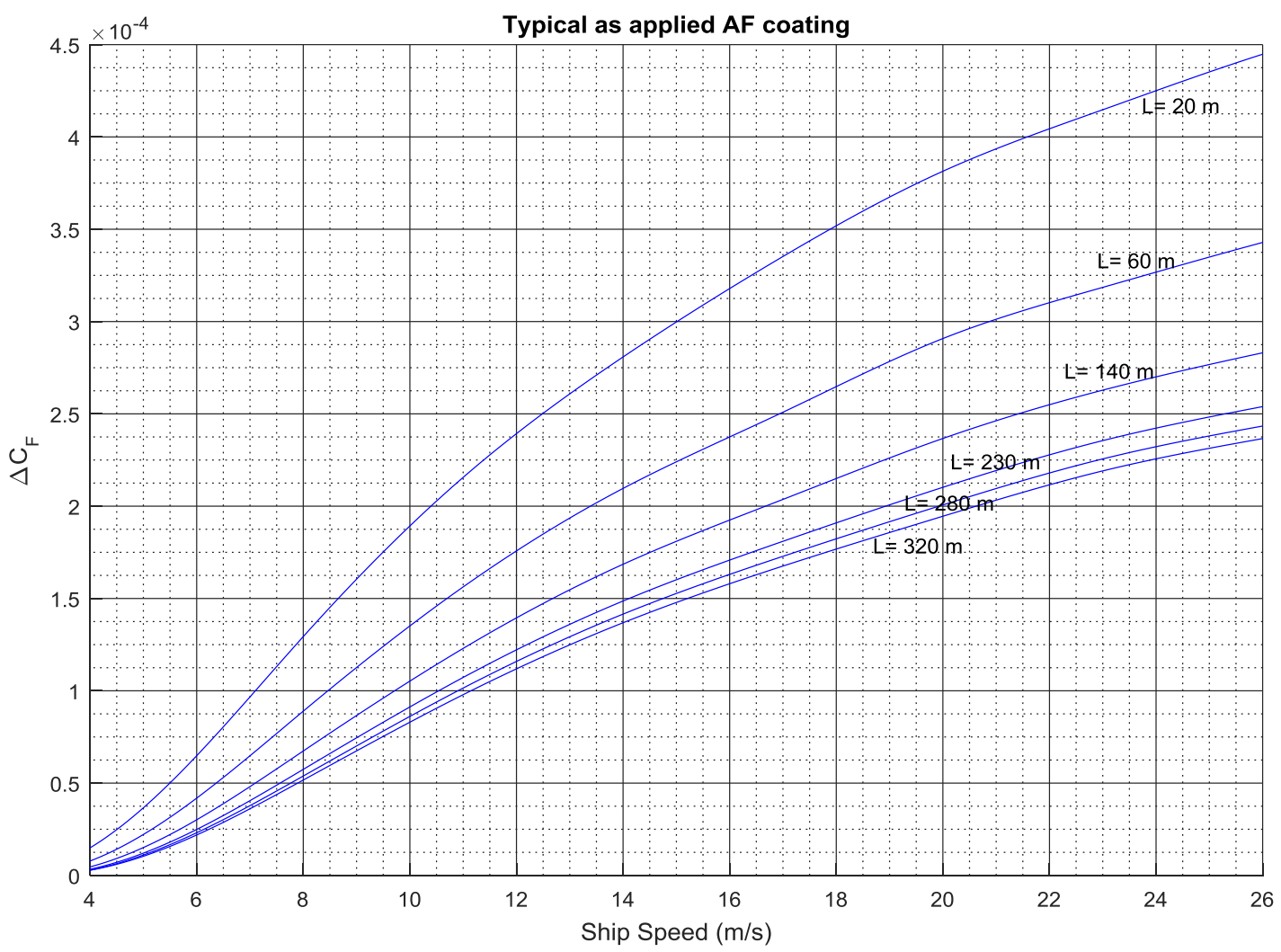

Figure 3: Added resistance diagram for ships with a typical as applied AF coating. 


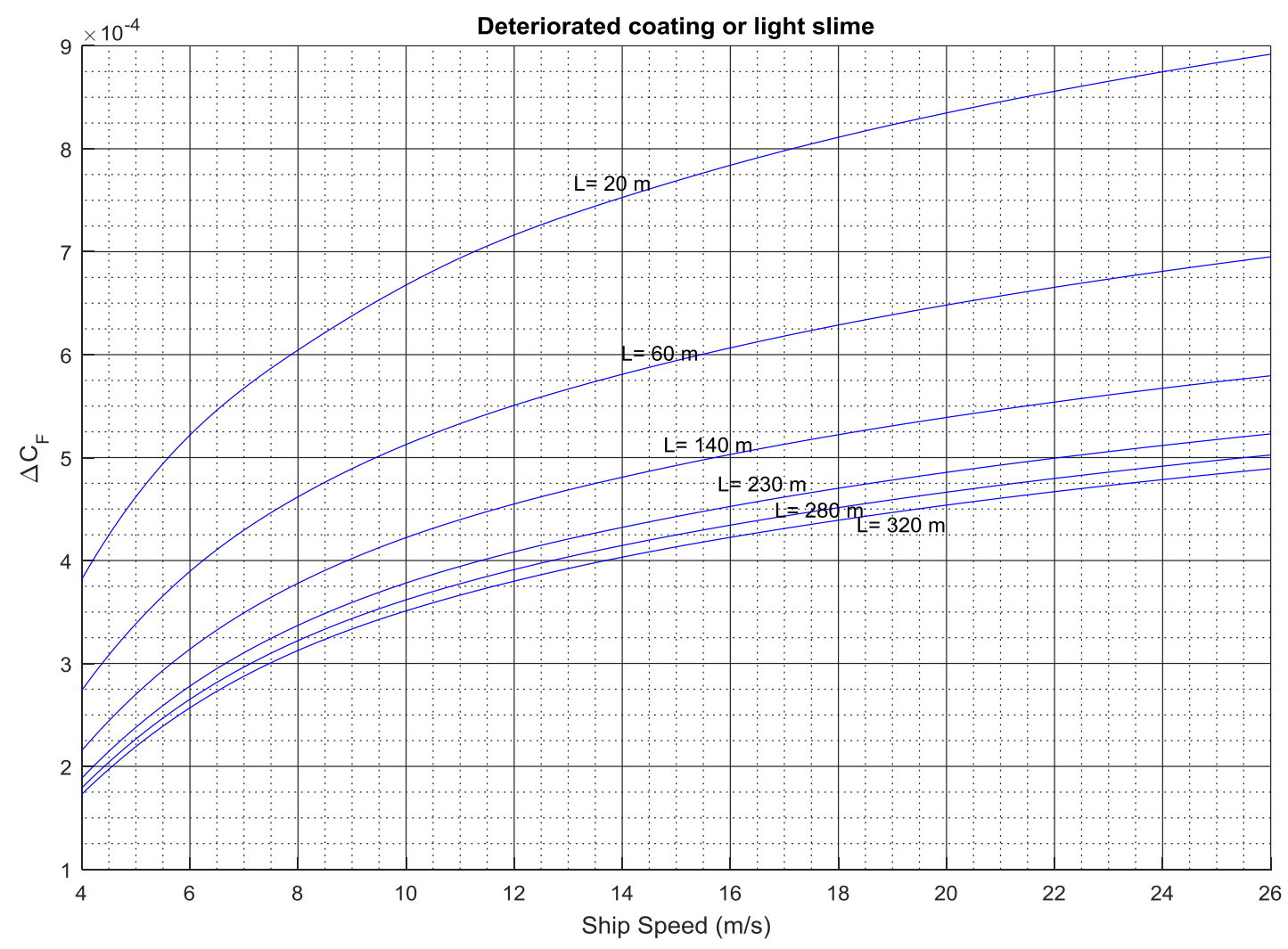

Figure 4: Added resistance diagram for ships with a deteriorated coating or light slime condition.

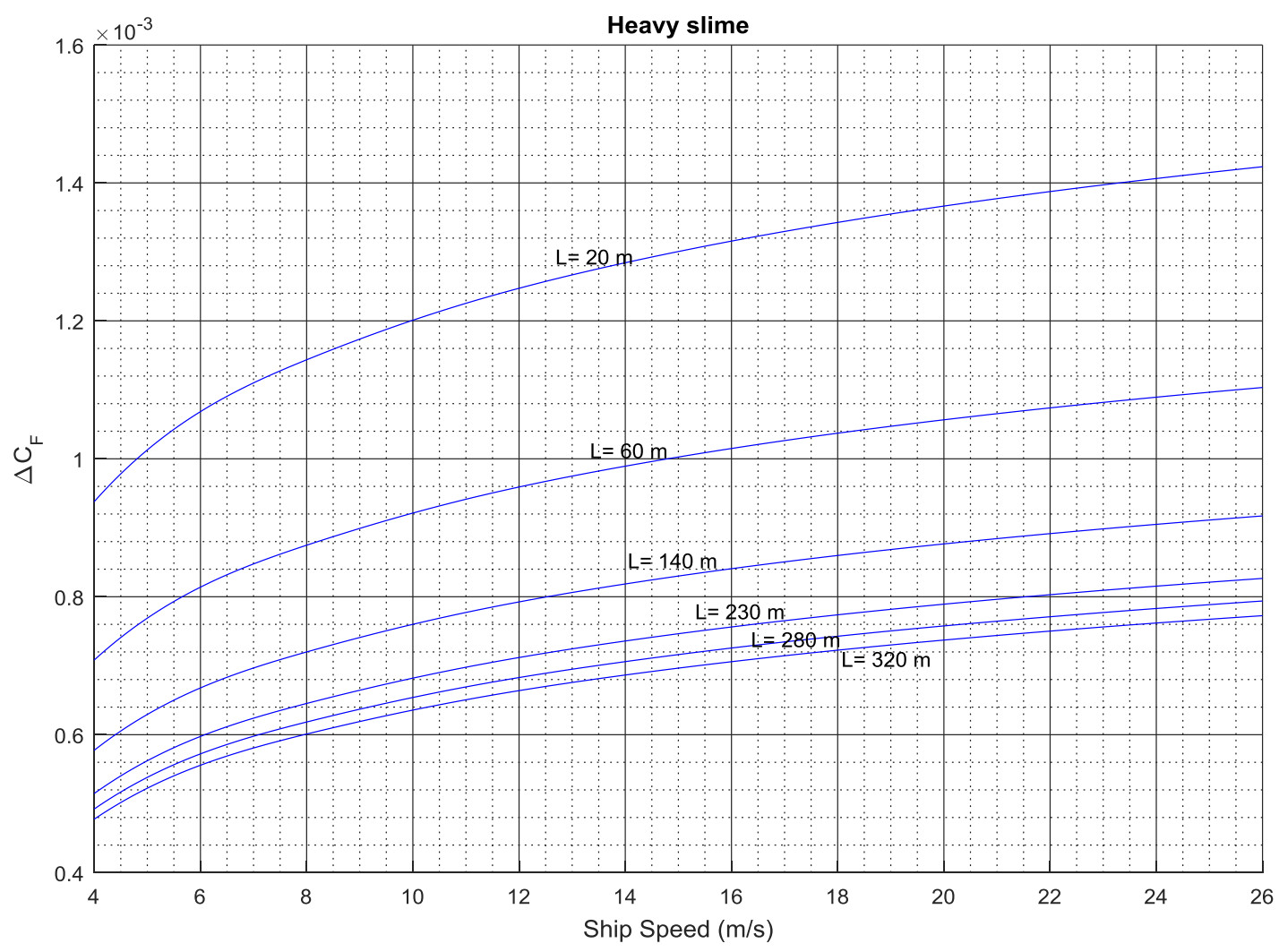

Figure 5: Added resistance diagram for ships with heavy slime. 


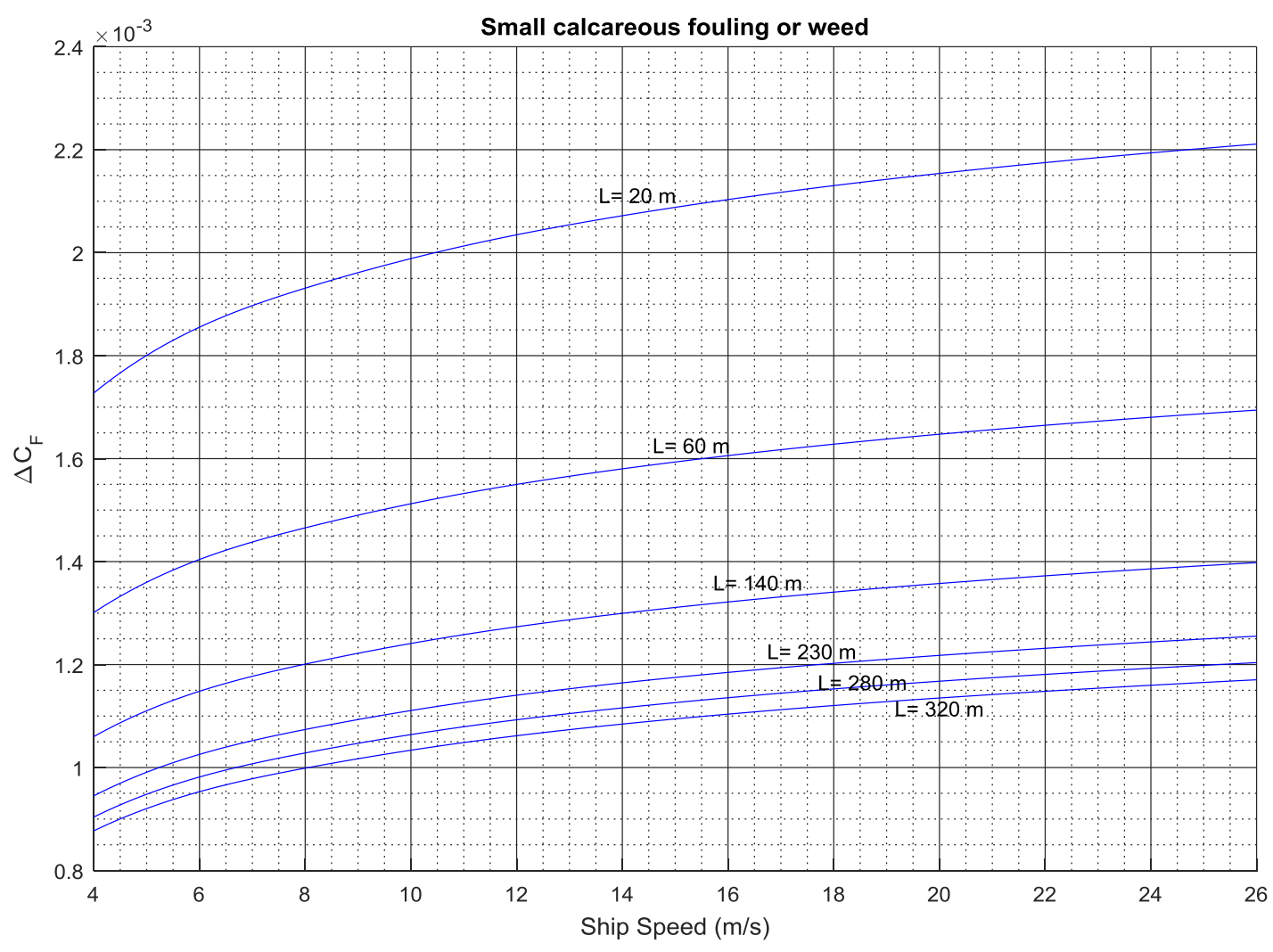

Figure 6: Added resistance diagram for ships with small calcareous fouling or weed.

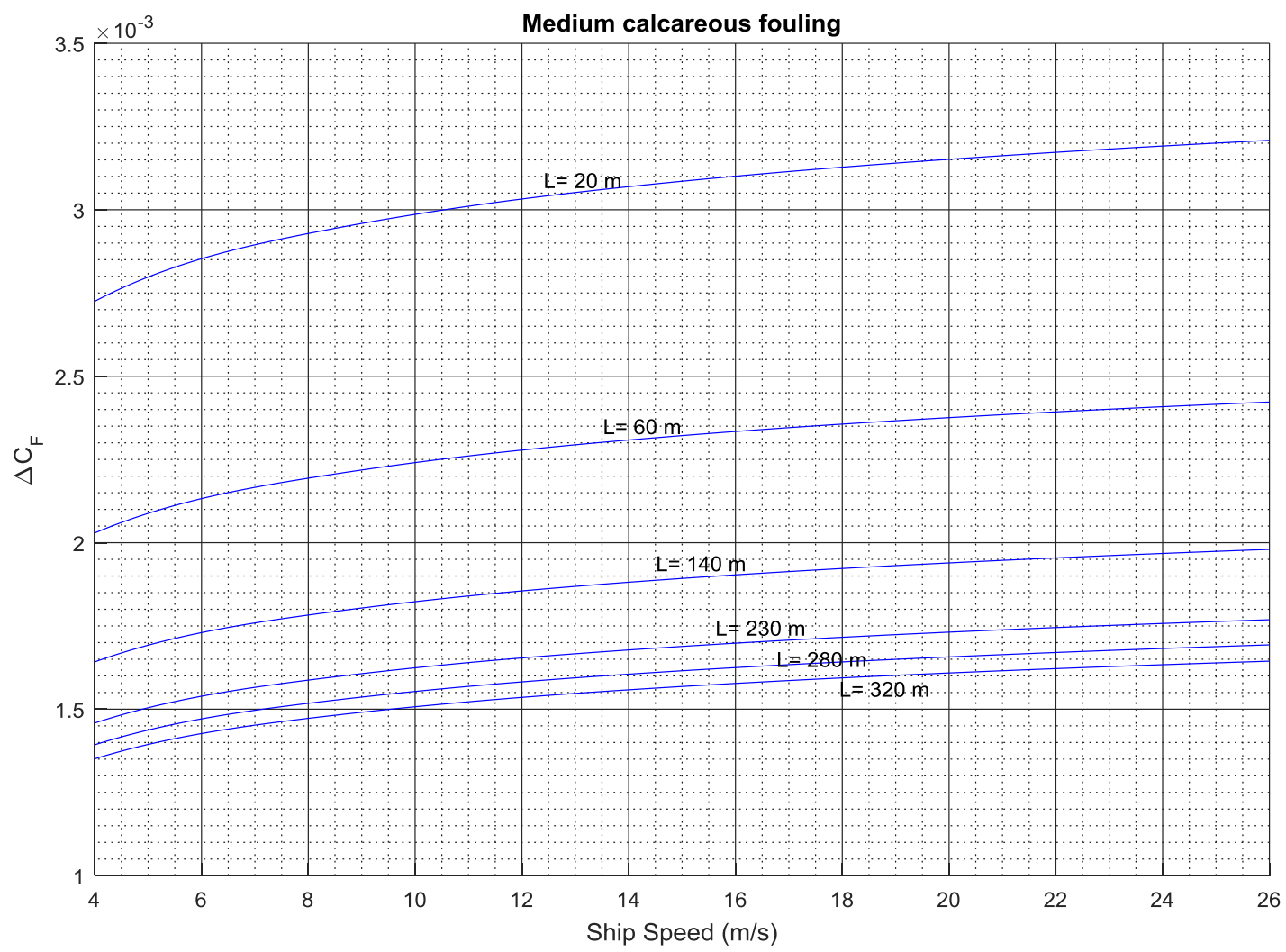

Figure 7: Added resistance diagram for ships with medium calcareous fouling. 


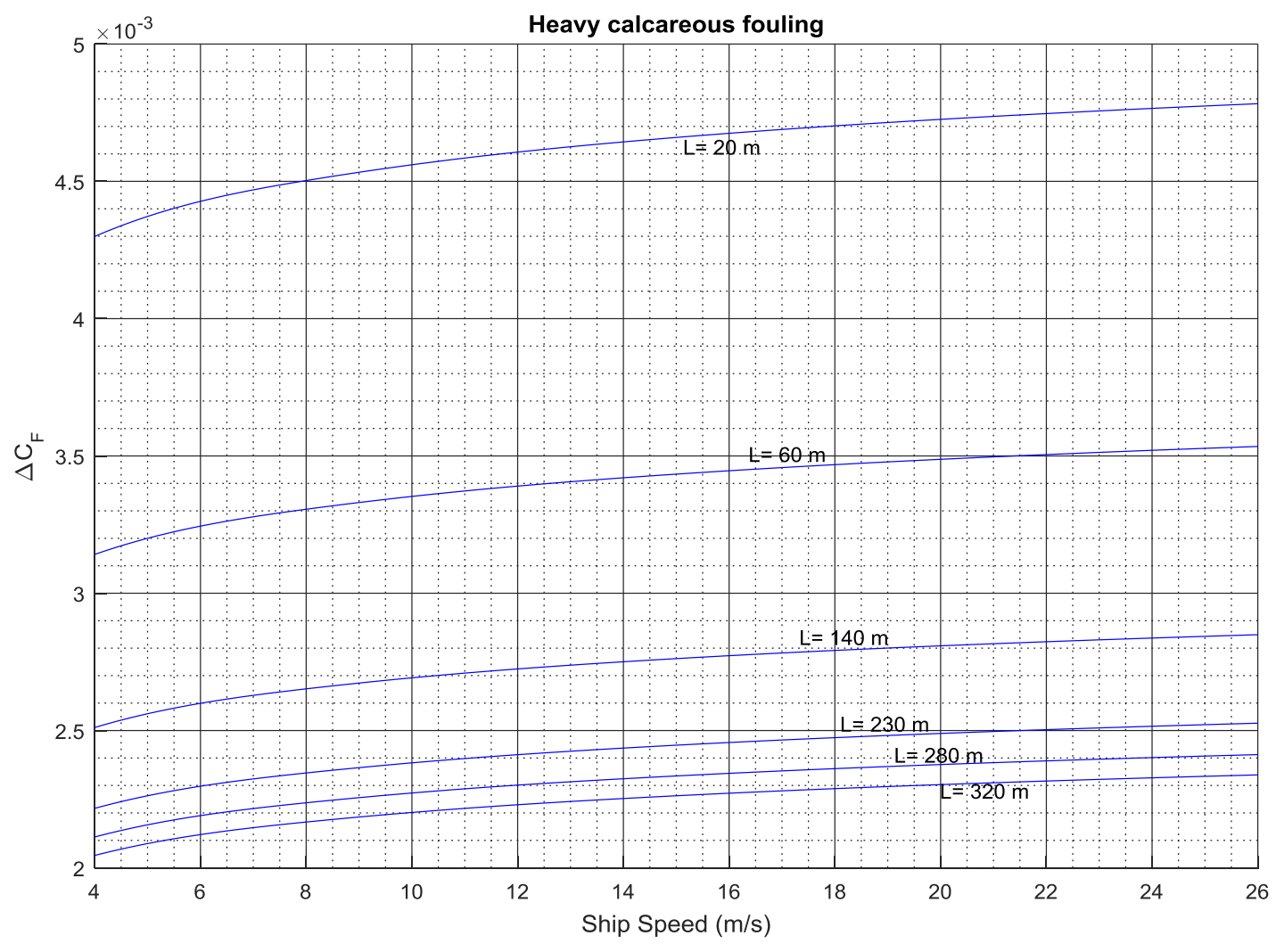

Figure 8: Added resistance diagram for ships with heavy calcareous fouling.

It is evidently seen from the above diagrams that the added resistance values increase with increasing ship speeds. More specifically, at low speeds, the rate of increase in the added frictional resistance coefficients is higher than the rate at higher speeds. Interestingly, this behaviour appears more clearly for the relatively smoother surfaces (e.g. typical as applied AF coating condition) compared to the rougher surfaces (e.g. calcareous fouling conditions).

As expected, the effect of roughness on the frictional resistance of flat plates varies depending on both the plate length and towing speed. For a given ship speed and surface roughness, a shorter plate will be subjected to a greater degree of added resistance than a longer plate. This observation suggests that the ratio between the roughness height and flat plate length is critical. Interestingly, a lot of variation can be observed between the graphs of the different surface roughness conditions. For example, looking at the surface with the lowest roughness (the as applied AF coating), the added frictional resistance coefficient decreases markedly with increasing plate length between $20 \mathrm{~m}$ and $140 \mathrm{~m}$, but for plate lengths of greater than $140 \mathrm{~m}$, the decrease becomes much lower. This can be seen more clearly from the diagrams including all ship lengths (10m to $400 \mathrm{~m}$ ), which can be found in Appendix (Figure A.1-A.24).

It is believed that these diagrams may serve as a simple prediction tool for naval architects and may be used to increase the awareness and emphasise the importance of biofouling mitigation on ship hulls, to ultimately enable more energy efficient ship operations.

\subsection{Added Resistance and Effective Power of Ships}

An increase in the frictional resistance would increase the required effective power, $\mathrm{P}_{\mathrm{E}}$, of a ship, which is the necessary power to move a ship through water. $\mathrm{P}_{\mathrm{E}}$ is related to the total resistance, $R_{T}$, and ship speed, V, which is defined by equation (4). 


$$
P_{E}=R_{T} V
$$

where

$$
R_{T}=\frac{1}{2} \rho S C_{T} V^{2}
$$

where $\mathrm{S}$ is the wetted surface area, $\mathrm{C}_{\mathrm{T}}$ is the total drag coefficient.

If we recall equation (5), we can then re-write equation (4) as

$$
P_{E}=\frac{1}{2} \rho S C_{T} V^{3}
$$

The increase in $\mathrm{P}_{\mathrm{E}}$ due to the effect of fouling can be expressed by

$$
\% \Delta P_{E}=\frac{C_{T, \text { rough }}-C_{T, \text { smooth }}}{C_{T, \text { smooth }}} \times 100=\frac{\Delta C_{F}}{C_{T, \text { smooth }}} \times 100
$$

similar to that used by Tezdogan et al. (2015). $\Delta \mathrm{C}_{\mathrm{F}}$ is the added resistance due to surface roughness and can be read from the diagrams given in the previous section. $\mathrm{C}_{\mathrm{T} \text {,smooth }}$ on the other hand, includes other resistance components and the evaluation of this is not the subject

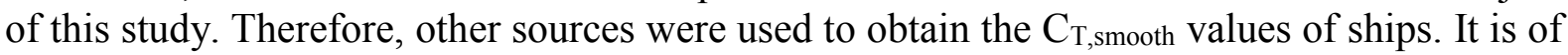
note that the current methodology does not take into account the roughness effect on other resistance components (e.g. viscous pressure resistance and wave making resistance) other than frictional resistance.

The predictions of the added effective powers of the six ships (yacht, research vessel, DTMB $5415, \mathrm{KCS}, \mathrm{JBC}$ and KVLCC2) were made using the generated diagrams (Figure 3 - Figure 8). The $\mathrm{C}_{\mathrm{T}}$, smooth values were either taken from the literature directly (Day and Cooper, 2011), extrapolated using the ITTC 1957 model-ship correlation line and the residuary resistance coefficients $\left(C_{R}\right.$, smooth $)$ obtained from experiments (Kim et al. 2011; NMRI 2015), or taken from the report of the experiments that were performed earlier in the Kelvin Hydrodynamics Laboratory at the University of Strathclyde. Table 2 shows the lengths of the ships and the speeds used to predict the added effective power due to the fouling conditions.

Table 2: Lengths and speeds of the ships for the case study

\begin{tabular}{lcccccc}
\hline & $\begin{array}{c}\text { IMOCA } \\
\text { Open 60 } \\
\text { class } \\
\text { yacht }\end{array}$ & $\begin{array}{c}\text { Training } \\
\text { and } \\
\text { research } \\
\text { vessel }\end{array}$ & $\begin{array}{c}\text { DTMB } \\
5415\end{array}$ & KCS & JBC & KVLCC2 \\
\hline Length (m) & 20 & 60 & 140 & 230 & 280 & 320 \\
Speed (m/s) & 7.72 & 6.17 & 15.43 & 12.35 & 7.45 & 7.97 \\
\hline
\end{tabular}

Table 3 and Table 4 illustrate the percentage increase in the frictional resistances and effective powers of the ships, respectively, calculated using the $\Delta \mathrm{C}_{\mathrm{F}}$ values obtained using the added resistance diagrams. Figure 9 and 10 visualises the percentage increase in the frictional resistance and effective powers. 
Table 3: The percentage increases in the frictional resistance $\left(\% \Delta C_{F}\right)$ due to the fouling conditions

\begin{tabular}{lcccccc}
\hline & $\begin{array}{c}\text { IMOCA } \\
\text { Open 60 } \\
\text { class } \\
\text { yacht }\end{array}$ & $\begin{array}{c}\text { Training } \\
\text { and } \\
\text { research } \\
\text { vessel }\end{array}$ & $\begin{array}{c}\text { DTMB } \\
5415\end{array}$ & KCS & JBC & $\begin{array}{c}\text { KVLCC } \\
2\end{array}$ \\
$\begin{array}{l}\text { Description of condition } \\
\begin{array}{l}\text { Typical as applied AF } \\
\text { coating }\end{array}\end{array} \quad 6 \%$ & $3 \%$ & $13 \%$ & $9 \%$ & $3 \%$ & $4 \%$ \\
$\begin{array}{l}\text { Deteriorated coating or light } \\
\text { slime }\end{array}$ & $28 \%$ & $22 \%$ & $35 \%$ & $30 \%$ & $21 \%$ & $20 \%$ \\
$\begin{array}{l}\text { Heavy slime } \\
\text { Small calcareous fouling or }\end{array}$ & $54 \%$ & $46 \%$ & $58 \%$ & $51 \%$ & $42 \%$ & $43 \%$ \\
weed & $14 \%$ & $79 \%$ & $92 \%$ & $84 \%$ & $74 \%$ & $72 \%$ \\
$\begin{array}{l}\text { Medium calcareous fouling } \\
\text { Heavy calcareous fouling }\end{array}$ & $221 \%$ & $183 \%$ & $194 \%$ & $174 \%$ & $155 \%$ & $153 \%$ \\
\hline
\end{tabular}

Table 4: The percentage increases in the effective power $\left(\% \Delta \mathrm{PE}_{\mathrm{E}}\right)$ due to the fouling conditions

\begin{tabular}{|c|c|c|c|c|c|c|}
\hline Description of condition & $\begin{array}{c}\text { IMOCA } \\
\text { Open } 60 \\
\text { class } \\
\text { yacht }\end{array}$ & $\begin{array}{l}\text { Training } \\
\text { and } \\
\text { research } \\
\text { vessel }\end{array}$ & $\begin{array}{l}\text { DTMB } \\
5415\end{array}$ & $\mathrm{KCS}$ & $\mathrm{JBC}$ & KVLCC2 \\
\hline $\begin{array}{l}\text { Typical as applied } \\
\text { coating }\end{array}$ & $2 \%$ & $1 \%$ & $3 \%$ & $6 \%$ & $2 \%$ & $2 \%$ \\
\hline $\begin{array}{l}\text { Deteriorated coating or light } \\
\text { slime }\end{array}$ & $11 \%$ & $9 \%$ & $9 \%$ & $19 \%$ & $12 \%$ & $14 \%$ \\
\hline Heavy slime & $22 \%$ & $19 \%$ & $15 \%$ & $33 \%$ & $23 \%$ & $29 \%$ \\
\hline $\begin{array}{l}\text { Small calcareous fouling or } \\
\text { weed }\end{array}$ & $38 \%$ & $32 \%$ & $24 \%$ & $54 \%$ & $41 \%$ & $49 \%$ \\
\hline Medium calcareous fouling & $57 \%$ & $50 \%$ & $35 \%$ & $80 \%$ & $59 \%$ & $71 \%$ \\
\hline Heavy calcareous fouling & $88 \%$ & $75 \%$ & $51 \%$ & $113 \%$ & $86 \%$ & $104 \%$ \\
\hline
\end{tabular}




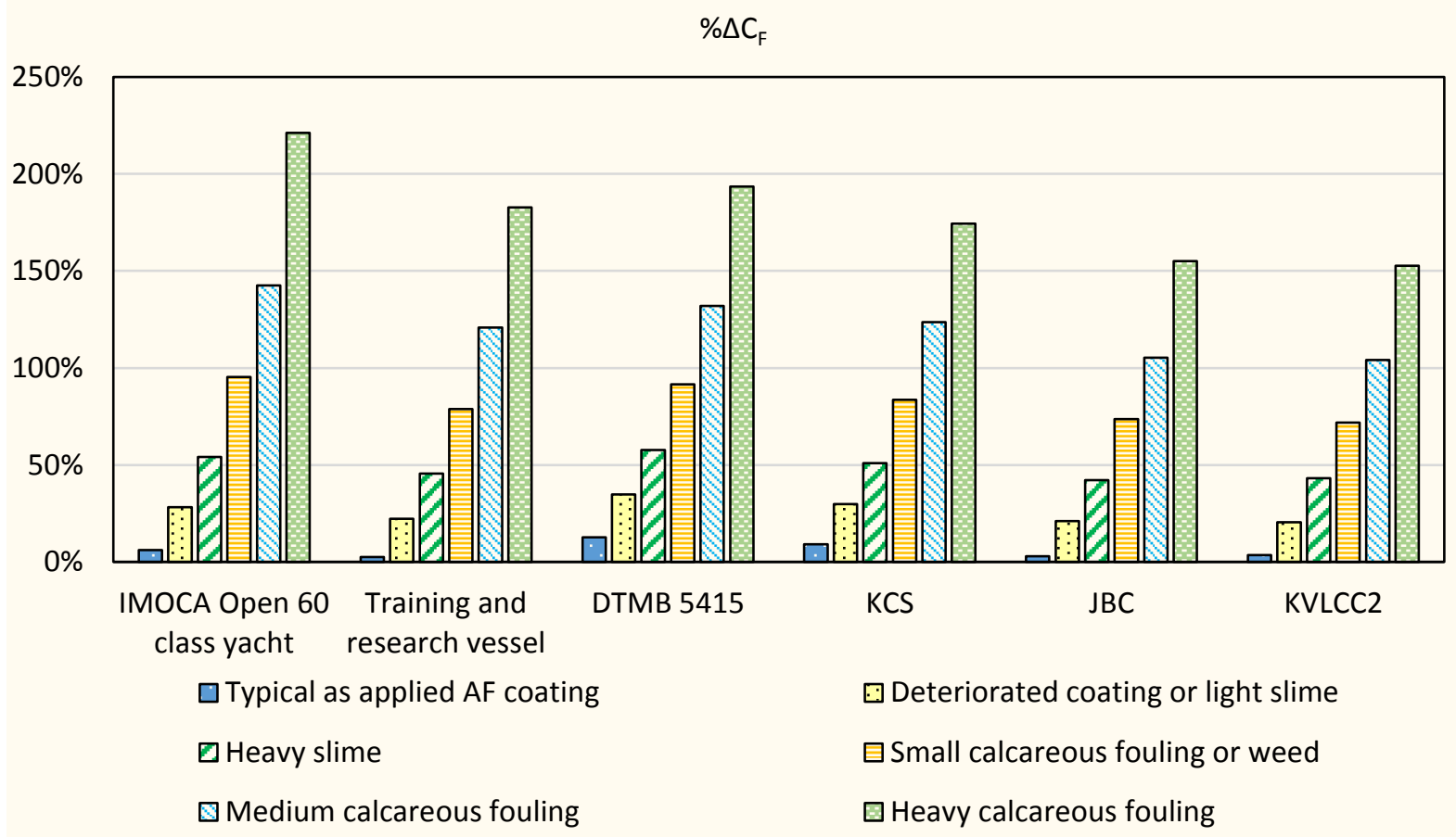

Figure 9: The percentage increases in the frictional resistance $\left(\% \Delta C_{F}\right)$ due to the fouling conditions

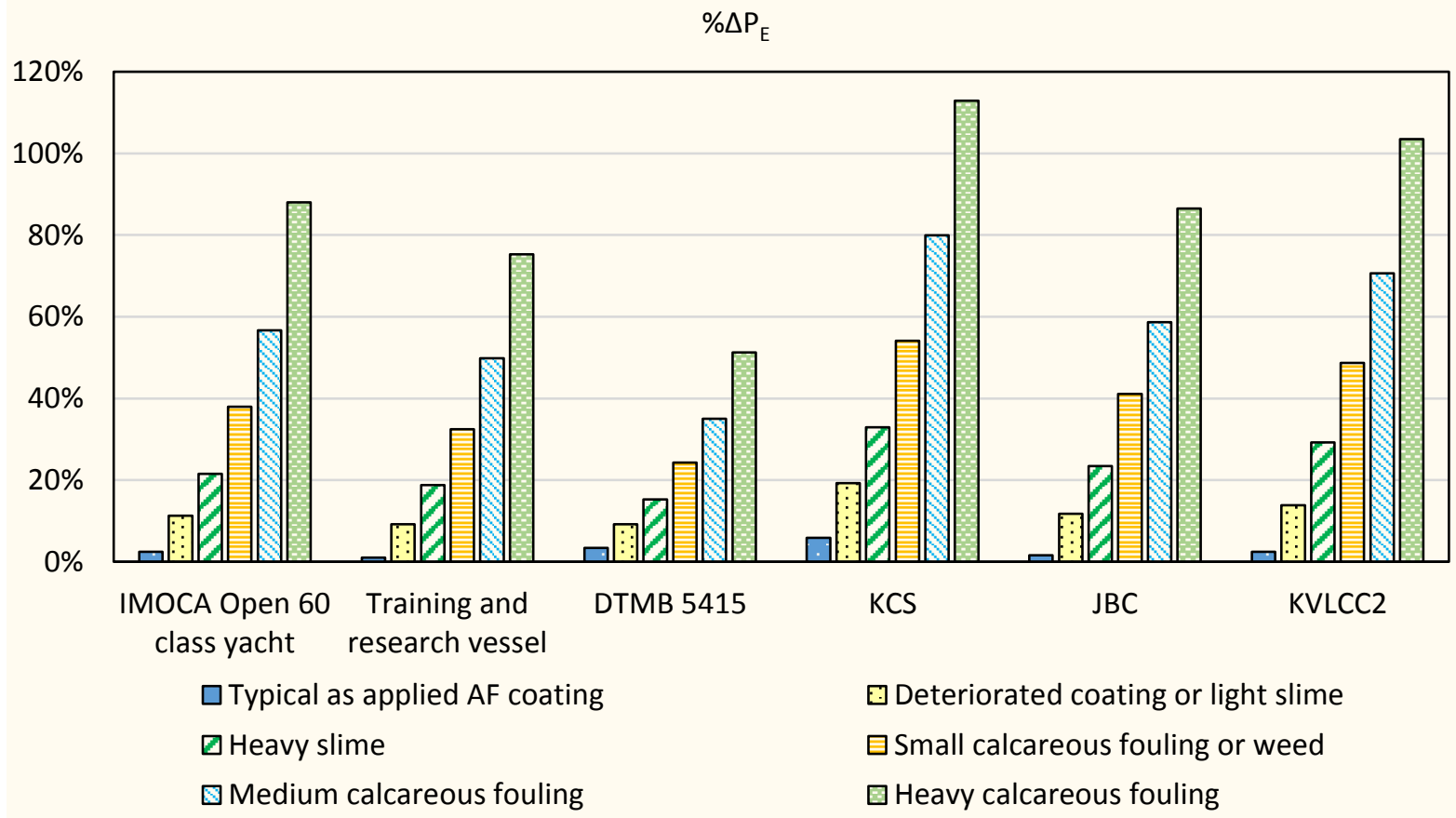

Figure 10: The percentage increases in the effective power $\left(\% \Delta \mathrm{P}_{E}\right)$ due to the fouling conditions

As shown in Table 3 and Figure 9, the increases in $\mathrm{C}_{\mathrm{F}}$ of the ships due to the hull roughness of a typical AF coating are relatively insignificant, whereas the increases in $\mathrm{C}_{\mathrm{F}}$ due to biofouling are predicted to be dramatic, which can lead to a drastic increase in the ship'sfuel consumption and hence $\mathrm{CO}_{2}$ emissions. Interestingly, the added resistance values due to the hull roughness of a typical AF coating for the DTMB 5415 and the KCS are relatively large $(13 \%$ and $9 \%$, respectively) compared to other ships under the same surface condition. This higher impact of 
the coating roughness on the added resistance of the DTMB 5415 and the KCS can be attributed to their relatively high speed, as can be seen from Figure 3. This suggests that the choice of proper coatings can be especially critical for high-speed ships. When it comes to the effect of other fouling conditions, the percentage increase in the frictional resistance appeared to be inversely proportional to the ship length, apart from the case of the DTMB 5415 which has a relatively high increase in $\mathrm{C}_{\mathrm{F}}$ due to its high design speed. Accordingly, the $20 \mathrm{~m}$-long yacht showed the highest percentage increase in the frictional resistance (e.g. 54\% due to heavy slime and $221 \%$ due to heavy calcareous fouling).

Unlike the increases in $\mathrm{C}_{\mathrm{F}}$ which showed a reversely proportional trend to the ship length, the percentage increase in the effective power, $\mathrm{P}_{\mathrm{E}}$, showed a different result as shown in Figure 9 and Figure 10. Interestingly, the percentage increase in $\mathrm{P}_{\mathrm{E}}$ for the commercial ships (KCS, JBC and KVLCC2) are rather high considering the relatively small increases in $\mathrm{C}_{\mathrm{F}}$ for those ships. This can be attributed to the fact that these commercial ships were designed to have less residuary resistance coefficients, $C_{R}$, and hence the contributions of the frictional resistance in the total resistance are relatively large. Accordingly, the increases in frictional resistance result in a larger impact on the total resistance and thus the effective power for these commercial vessels. The increases in $\mathrm{P}_{\mathrm{E}}$ due to the surface conditions for the KCS, JBC and KVLCC2 were predicted to be up to $113 \%, 86 \%$, and $104 \%$, respectively, under heavy calcareous fouling condition.

\section{DISCUSSION AND CONCLUSIONS}

Firstly, an in-house prediction code based on the similarity law analysis of Granville (1958) was developed to rapidly and accurately predict the effect of a given roughness on the frictional resistance of full-scale ships with arbitrary lengths and speeds.

Predictions of the effect of a range of representative coating and biofouling conditions were then made using the developed code. The roughness functions of such conditions were assumed to follow the roughness function behaviours of the ones provided by Schultz and Flack (2007) and the fouling conditions were assumed to be represented by the roughness length scales proposed by Schultz (2007). These were employed in the aforementioned in-house code and, using this approach, an extensive database of $\Delta \mathrm{C}_{\mathrm{F}}$ as functions of fouling conditions, ship lengths and ship speeds was generated. The added resistance diagrams were then generated using this database. In their current state, these diagrams can be used to predict the effects of a range of representative coating and fouling conditions defined by Schultz (2007). It is of note that this approach assumes a homogenous distribution of fouling on a ship hull, which may not necessarily be the case on real ship hulls. Therefore, additional results from further immersion tests and experiments considering different types of fouling and their spatial distributions would be beneficial to improve the diagrams. Having said that, the present diagrams may be considered as a leap forward towards a universal model.

The diagrams have a key advantage in that they capture the complex hydrodynamic response of fouling in simple curves which can be implemented in a spreadsheet or a tool for life-cycle cost estimation. The main advantage of the proposed diagrams is that they directly enable the use of surface conditions, ship length and ship speed, rather than having to use hydrodynamic parameters. By using the diagrams, one can easily estimate the added resistance, and hence the fuel penalty, of a ship for a particular fouling condition. Therefore, it becomes very practical to calculate the effect of a range of representative coating and fouling conditions on frictional resistance.

This paper not only proposes practical added resistance diagrams to predict fouling impact on ship performance but also provides the algorithm of the prediction procedure showing how to develop such diagrams using the available experimental data. This means that once future 
experimental data is available, the developed in-house code can be operated again and new diagrams can be developed quickly and easily.

However, the added resistance diagrams presented in this study do not consider the roughness effect on other resistance components (e.g. viscous pressure resistance and wave making resistance) apart from the frictional resistance. Also, the frictional resistance was predicted based on flat plate representations, and the increase in frictional resistance would not be the same for a flat plate and a 3D ship hull. Another point to note is that the selected roughness function model may not necessarily work for other surfaces as Candries and Atlar (2003) and Schultz et al. (2015) discussed the lack of collapse of coated/fouled surfaces onto one equation. It is recommended that the applicability of the roughness function model for different coated/fouled surfaces should be investigated in the future.Further research is also recommended in order to define the surfaces and roughness functions in more complex ways, such as by considering the spatial distribution of fouling, or its percentage coverage on a hull.

\section{ACKNOWLEDGEMENTS}

The authors are grateful for the EPSRC support for the project on 'Shipping in Changing Climates' (EPSRC Grant No. EP/K039253/1), which enabled them to carry out the research reported in this paper.

The authors acknowledge that the research presented in this paper was partially generated as part of the EU funded FP7 project FOUL-X-SPEL (Environmentally Friendly Antifouling Technology to Optimise the Energy Efficiency of Ships, Project number 285552, FP7-SST2011-RTD-1).

\section{REFERENCES}

Andrewartha, J., Perkins, K., Sargison, J., Osborn, J., Walker, G., Henderson, A., Hallegraeff, G., 2010. Drag force and surface roughness measurements on freshwater biofouled surfaces, Biofouling. Taylor \& Francis, pp. 487-496.

Atlar, M., Yeginbayeva, I. A., Turkmen, S., Demirel, Y. K., Carchen, A., Marino, A., \& Williams, D., 2018, A Rational Approach to Predicting the Effect of Fouling Control Systems on "In-Service" Ship Performance. GMO SHIPMAR, 24(213), 5-36.

Candries, M. and Atlar, M., 2003. On the drag and roughness characteristics of antifoulings. International Journal of Maritime Engineering 145(A2): 36-60

Corbett, J., E James, P., Winebrake, J., Bryan Comer, E., \& Green., 2011. Energy and GHG Emissions Savings Analysis of Fluoropolymer Foul Release Hull Coating: Energy and Environmental Research Associates, LLC.

Benson, J., Ebert, J., Beery, T., 1938. Investigation in the NACA tank of the effect of immersion in salt water on the resistance of plates coated with different shipbottom paints. NACA Memorandum Report C\&R C-S19-1(3).

Day, A. H., \& Cooper, C. (2011). An experimental study of interceptors for drag reduction on high-performance sailing yachts. Ocean Engineering, 38(8), 983-994. doi: https://doi.org/10.1016/j.oceaneng.2011.03.006

Demirel, Y.K., 2015. Modelling the roughness effects of marine coatings and biofouling on ship frictional resistance, Department of Naval Architecture, Ocean and Marine Engineering. University of Strathclyde.

Demirel, Y.K., Khorasanchi, M., Turan, O., Incecik, A., 2013. On the importance of antifouling coatings regarding ship resistance and powering, 3rd International Conference on Technologies, Operations, Logistics and Modelling for Low Carbon Shipping, London/UK. 
Demirel, Y.K., Khorasanchi, M., Turan, O., Incecik, A., Schultz, M.P., 2014. A CFD model for the frictional resistance prediction of antifouling coatings. Ocean Engineering 89, 21-31. Demirel, Y.K., Turan, O., Incecik, A., 2017. Predicting the effect of biofouling on ship resistance using CFD. Applied Ocean Research 62, 100-118.

Demirel, Y. K., Uzun, D., Zhang, Y., Fang, H.-C., Day, A. H., \& Turan, O., 2017a. Effect of barnacle fouling on ship resistance and powering. Biofouling, 33(10), 819-834. doi: 10.1080/08927014.2017.1373279

Farkas, A., Degiuli, N., \& Martić, I., 2018, Towards the prediction of the effect of biofilm on the ship resistance using CFD. Ocean Engineering, 167, 169-186. doi: https://doi.org/10.1016/j.oceaneng.2018.08.055

Flack, K.A., Schultz, M.P., 2010. Review of Hydraulic Roughness Scales in the Fully Rough Regime. Journal of fluids engineering 132 (4), 041203-041203.

Gowing, S., Chang, P., Dehn, C., \& Storms, S., 2018. Measurements of biofouling drag using a 2-D channel flow apparatus with models of bio-fouled panels. Paper presented at the 19th International Congress on Marine Corrosion and Fouling, Melbourne, Florida.

Granville, P.S., 1958. The frictional resistance and turbulent boundary layer of rough surfaces. Journal of ship research 2, 52-74.

Haslbeck, E.G., Bohlander, G., 1992. Microbial biofilm effects on drag-lab and field, 1992 Ship Production Symposium Proceedings, SNAME.

Hundley, L., Tate, C., 1980. Hull-fouling studies and ship powering trial results on seven FF 1052 class ships. D W Taylor Naval Ship Research and Development Center Report \# DTNSRDC-80/027. $111 \mathrm{p}$.

Izaquirre-Alza, P., Perez-Rojas, L., \& Nunez-Basanez, J. F., 2010, Drag reduction through special paints coated on the hull. Paper presented at the International Conference on Ship Drag Reduction SMOOTH-SHIPS, Istanbul, Turkey.

Kim, W.J., Van, S.H., Kim, D.H., 2001. Measurement of flows around modern commercial ship models. Experiments in Fluids 31 (5), 567-578.

Lewkowicz, A., Das, D., 1986. Turbulent boundary layers on rough surfaces with and without a pliable overlayer: a simulation of marine fouling. International Shipbuilding Progress 33, 174-186.

Loeb, G., Laster, D., Gracik, T., 1984. The influence of microbial fouling films on hydrodynamic drag of rotating discs, in: Costlow, J.D., Tipper, R. (Eds.), Marine Biodeterioration: An Interdisciplinary Study. Naval Institute Press, Annapolis, MD, pp. 88-94. Monty, J. P., Dogan, E., Hanson, R., Scardino, A. J., Ganapathisubramani, B., \& Hutchins, N., 2016. An assessment of the ship drag penalty arising from light calcareous tubeworm fouling. Biofouling, 32(4), 451-464. doi: 10.1080/08927014.2016.1148140

Munk, T., 2006. Fuel conservation through managing hull resistance. Paper presented at Motorship Propulsion conference, Copenhagen

Naval Ships' Technical Manual, 2002. Waterborne underwater hull cleaning of navy ships. S9086-CQ-STM-010/CH-081R5. Naval Sea Systems Command.

NMRI. (2015). Tokyo 2015: A Workshop on CFD in Ship Hydrodynamics Retrieved 20 Feb, 2019, from http://www.t2015.nmri.go.jp/

Owen, D., Demirel, Y. K., Oguz, E., Tezdogan, T., \& Incecik, A. (2018). Investigating the effect of biofouling on propeller characteristics using CFD. Ocean Engineering. doi: https://doi.org/10.1016/j.oceaneng.2018.01.087

Schultz, M.P., 1998. The Effect of Biofilms on Turbulent Boundary Layer Structure. Florida Institute of Technology.

Schultz, M.P., 2002. The relationship between frictional resistance and roughness for surfaces smoothed by sanding. Journal of fluids engineering 124 (2), 492-499. 
Schultz, M.P., 2004. Frictional resistance of antifouling coating systems. Journal of fluids engineering 126 (6), 1039-1047.

Schultz, M.P., 2007. Effects of coating roughness and biofouling on ship resistance and powering. Biofouling 23 (5), 331-341.

Schultz, M.P., Bendick, J.A., Holm, E.R., Hertel, W.M., 2011. Economic impact of biofouling on a naval surface ship. Biofouling 27 (1), 87-98.

Schultz, M.P., Flack, K., 2007. The rough-wall turbulent boundary layer from the hydraulically smooth to the fully rough regime. Journal of Fluid Mechanics 580, 381-405.

Schultz, M.P., Swain, G., 1999. The effect of biofilms on turbulent boundary layers. Journal of fluids engineering 121 (1), 44-51.

Schultz, M.P., Swain, G.W., 2000. The influence of biofilms on skin friction drag. Biofouling 15 (1-3), 129-139.

Schultz, M. P., Walker, J. M., Steppe, C. N., \& Flack, K. A., 2015. Impact of diatomaceous biofilms on the frictional drag of fouling-release coatings. Biofouling, 31(9-10), 759-773. doi: 10.1080/08927014.2015.1108407

Schoenherr KE., 1932, Resistances of flat surfaces moving through a fluid. Trans SNAME 40:279-313.

Shapiro, T.A., 2004. The effect of surface roughness on hydrodynamic drag and turbulence, USNA Trident Scholar Project Report No. 327.

Shockling, M.A., Allen, J.J., Smits, A.J., 2006. Roughness effects in turbulent pipe flow. Journal of Fluid Mechanics 564, 267-285.

Song, S., Demirel, Y. K., \& Atlar, M., 2019a. An investigation into the effect of biofouling on the ship hydrodynamic characteristics using CFD. Ocean Engineering, 175, 122-137. doi: https://doi.org/10.1016/j.oceaneng.2019.01.056

Song, S., Demirel, Y. K., \& Atlar, M., 2019b, June 9 - 14, 2019. An investigation into the effect of biofouling on full-scale propeller performance using CFD. Paper presented at the 38th International Conference on Ocean, Offshore \& Arctic Engineering, Glasgow.

Swain, G.W., Kovach, B., Touzot, A., Casse, F., Kavanagh, C.J., 2007. Measuring the Performance of Today's Antifouling Coatings. Journal of Ship Production 23 (3), 164-170.

T. Tezdogan, Y.K. Demirel, 2014 An overview of marine corrosion protection with a focus on cathodic protection and coatings, Brodogradnja 65, 49-59.

Tezdogan, T., Demirel, Y.K., Kellett, P., Khorasanchi, M., Incecik, A., Turan, O., 2015. Fullscale unsteady RANS CFD simulations of ship behaviour and performance in head seas due to slow steaming. Ocean Engineering 97 (0), 186-206.

Turan, O., Demirel, Y.K., Day, S., Tezdogan, T., 2016. Experimental Determination of Added Hydrodynamic Resistance Caused by Marine Biofouling on Ships. Transportation Research Procedia 14, 1649-1658.

Watanabe, S., Nagamatsu, N., Yokoo, K., Kawakami, Y., 1969. The augmentation in frictional resistance due to slime. J. Kansai Soc. Nav. Arc. 131, 45-51.

Womack, K. M., Schultz, M. P., \& Meneveau, C., 2018. Effect of barnacle density on hydrodynamic drag. Paper presented at the 19th International Congress on Marine Corrosion and Fouling, Melbourne, Florida. 


\section{Appendix}

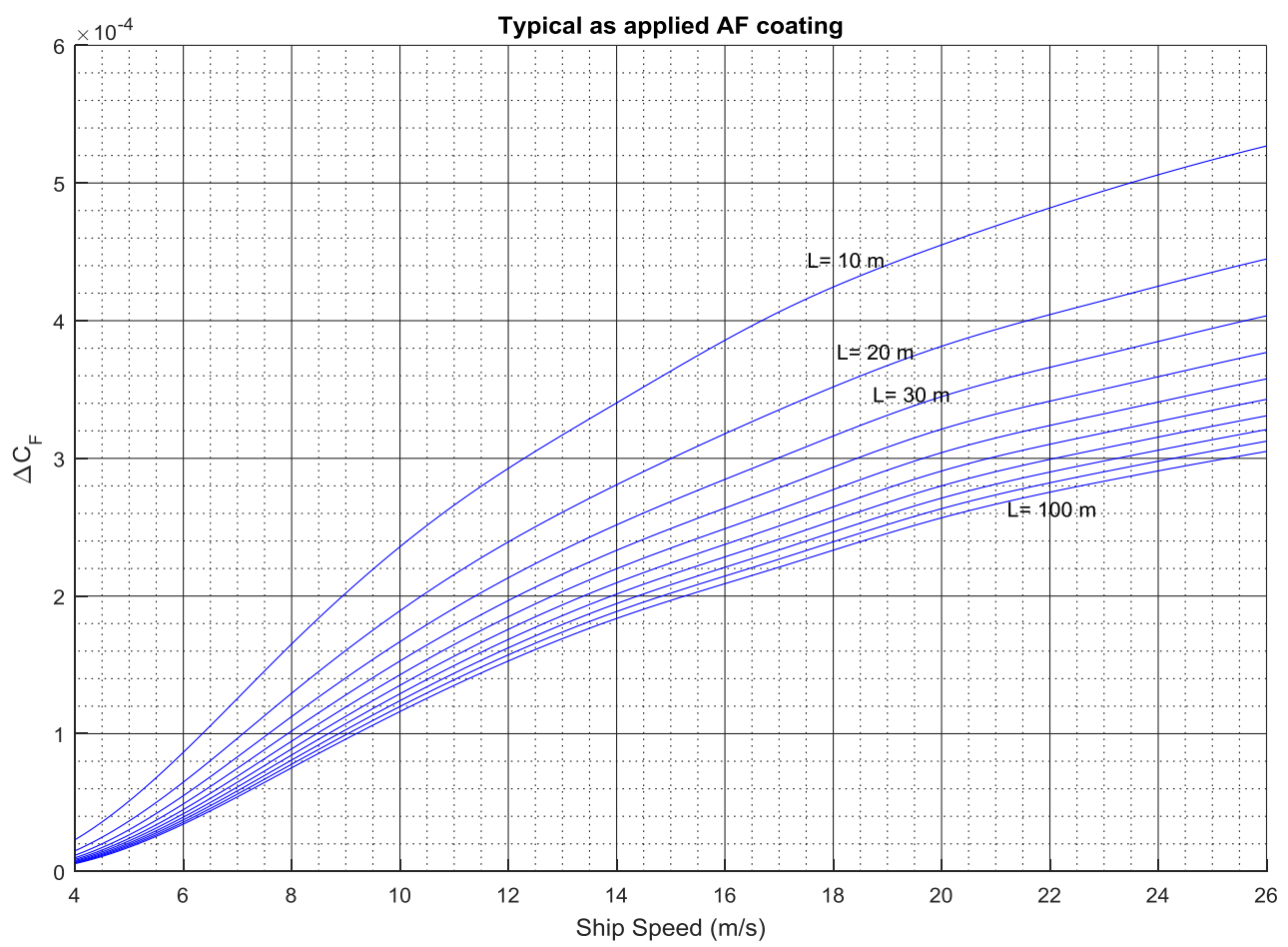

Figure A. 1 Added resistance diagram for ships with a typical as applied AF coating ( $\mathrm{L}=10-100 \mathrm{~m}, 10 \mathrm{~m}$ increments)

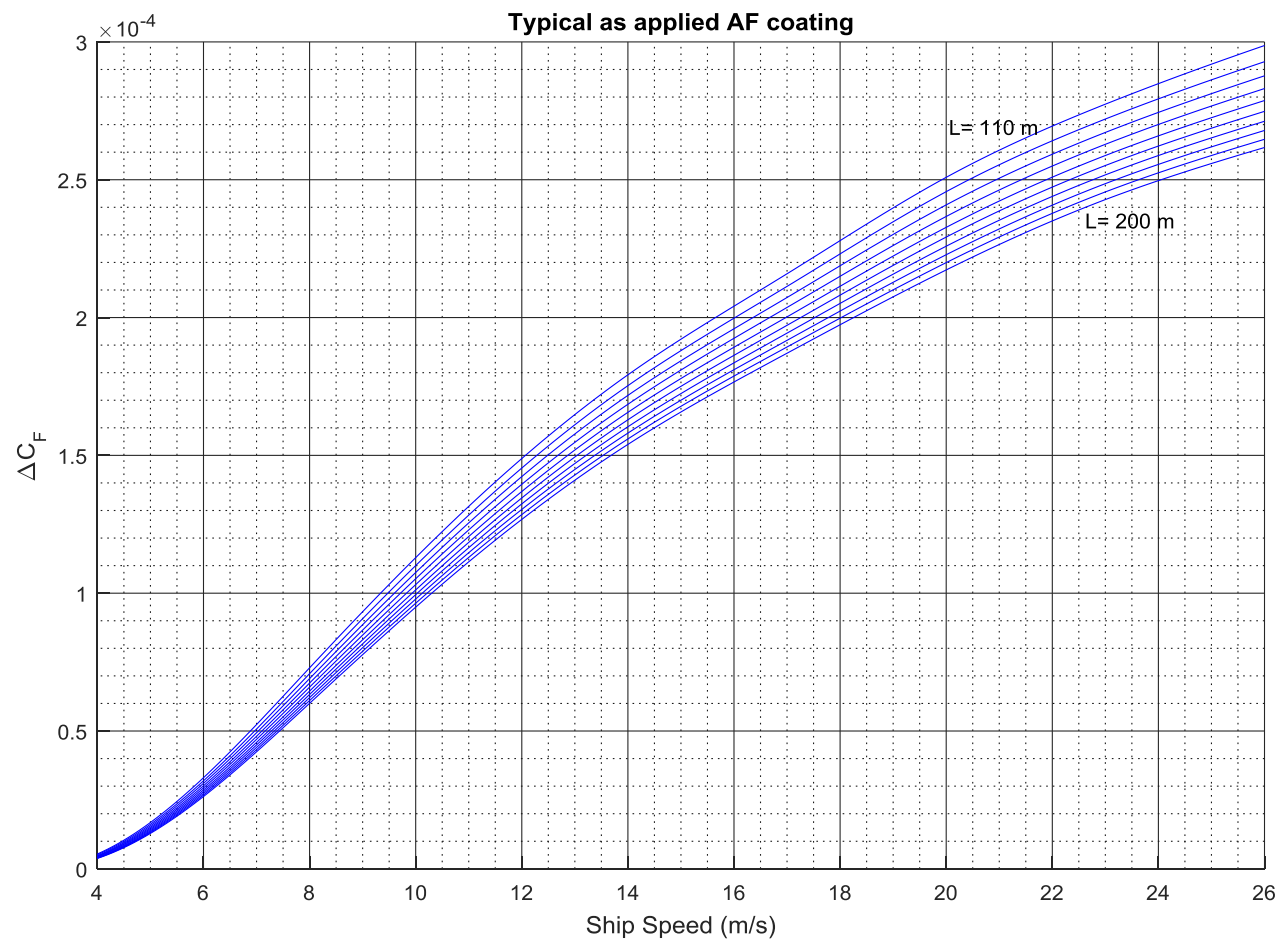

Figure A. 2 Added resistance diagram for ships with a typical as applied AF coating ( $\mathrm{L}=110-200 \mathrm{~m}, 10 \mathrm{~m}$ increments) 


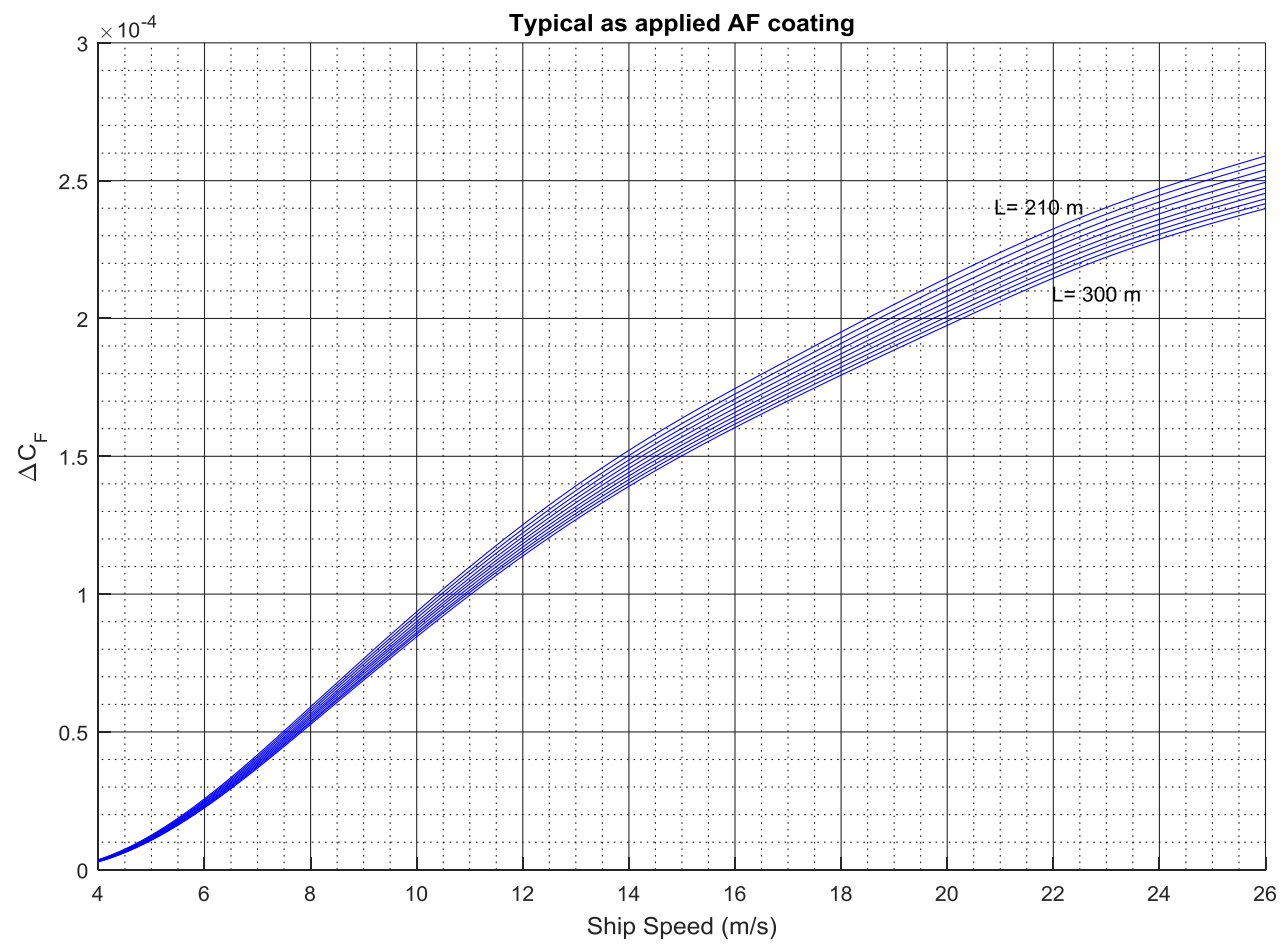

Figure A. 3 Added resistance diagram for ships with a typical as applied AF coating

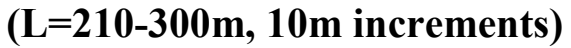

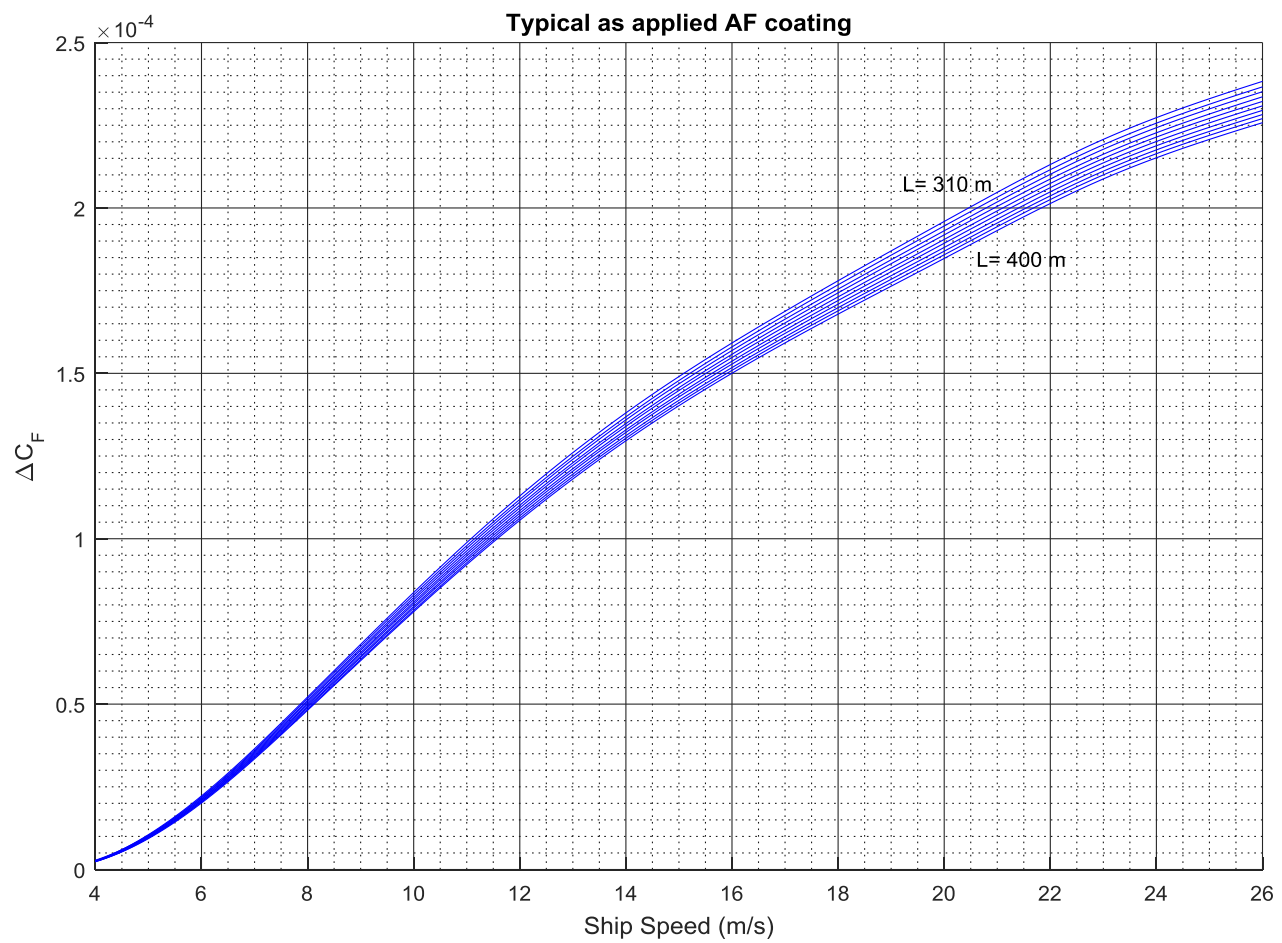

Figure A. 4 Added resistance diagram for ships with a typical as applied AF coating ( $\mathrm{L}=310-400 \mathrm{~m}, 10 \mathrm{~m}$ increments) 


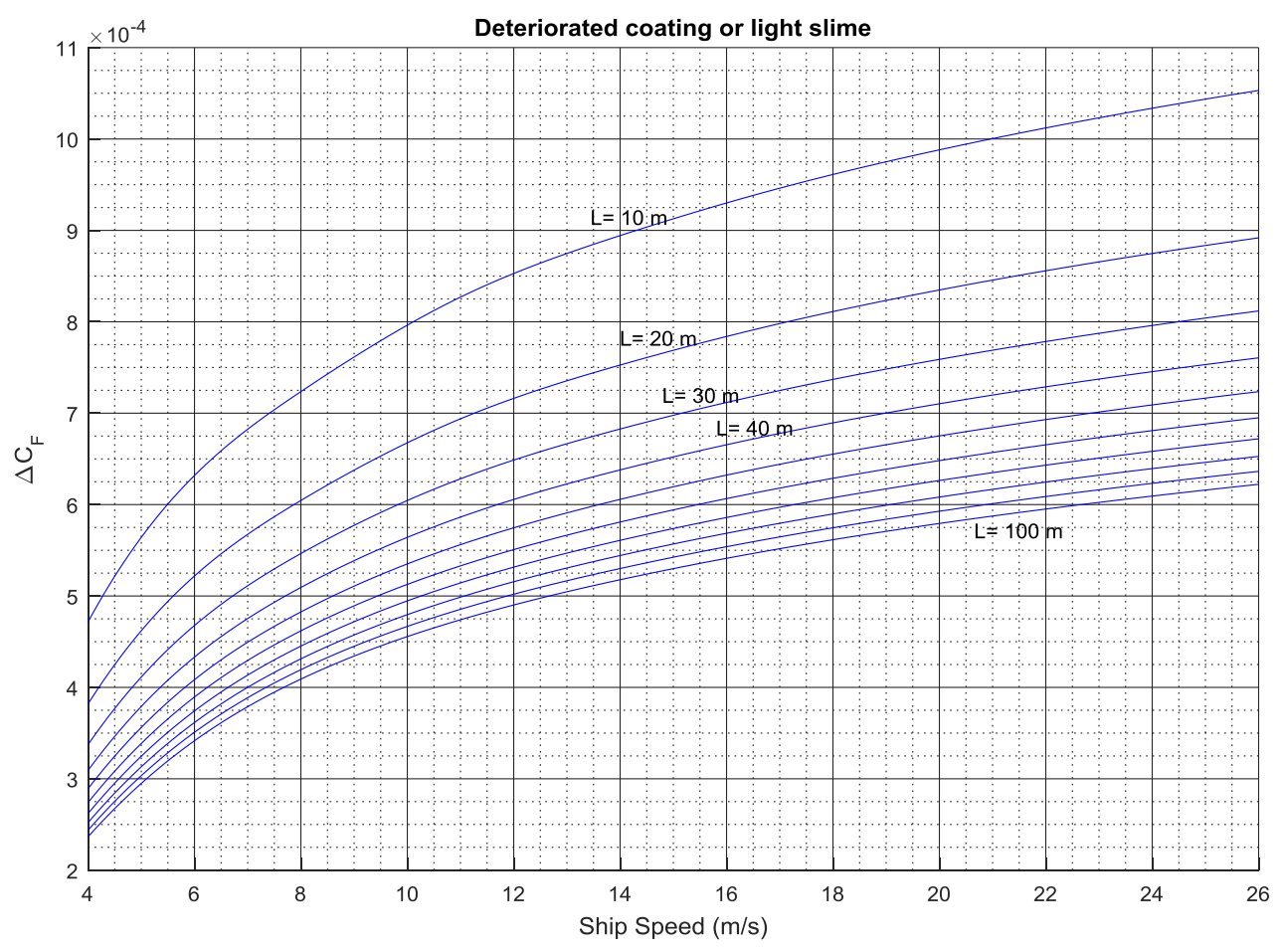

Figure A. 5 Added resistance diagram for ships with a deteriorated coating or light slime condition ( $L=10-100 \mathrm{~m}, 10 \mathrm{~m}$ increments)

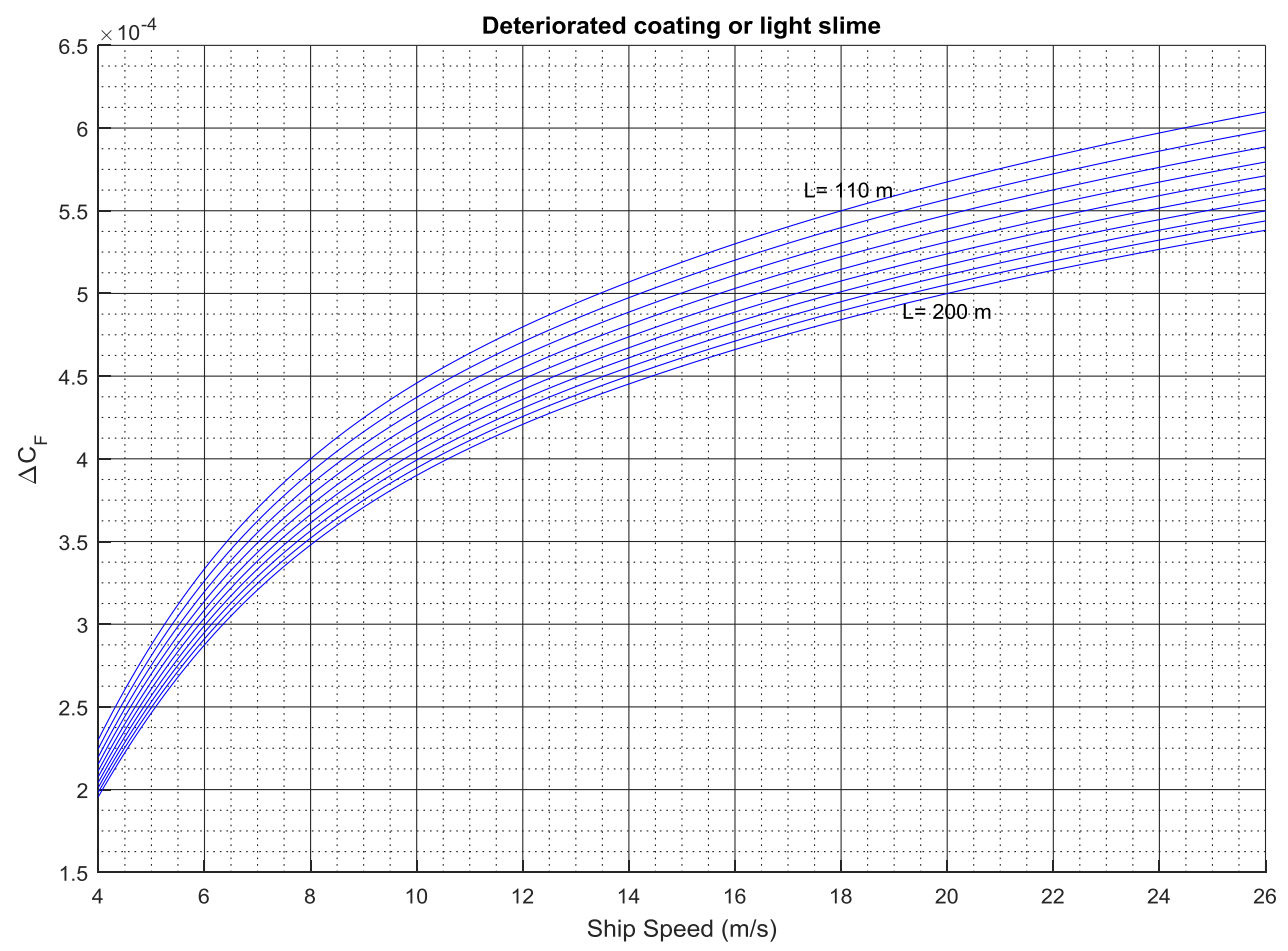

Figure A. 6 Added resistance diagram for ships with a deteriorated coating or light slime condition ( $\mathrm{L}=110-200 \mathrm{~m}, 10 \mathrm{~m}$ increments) 


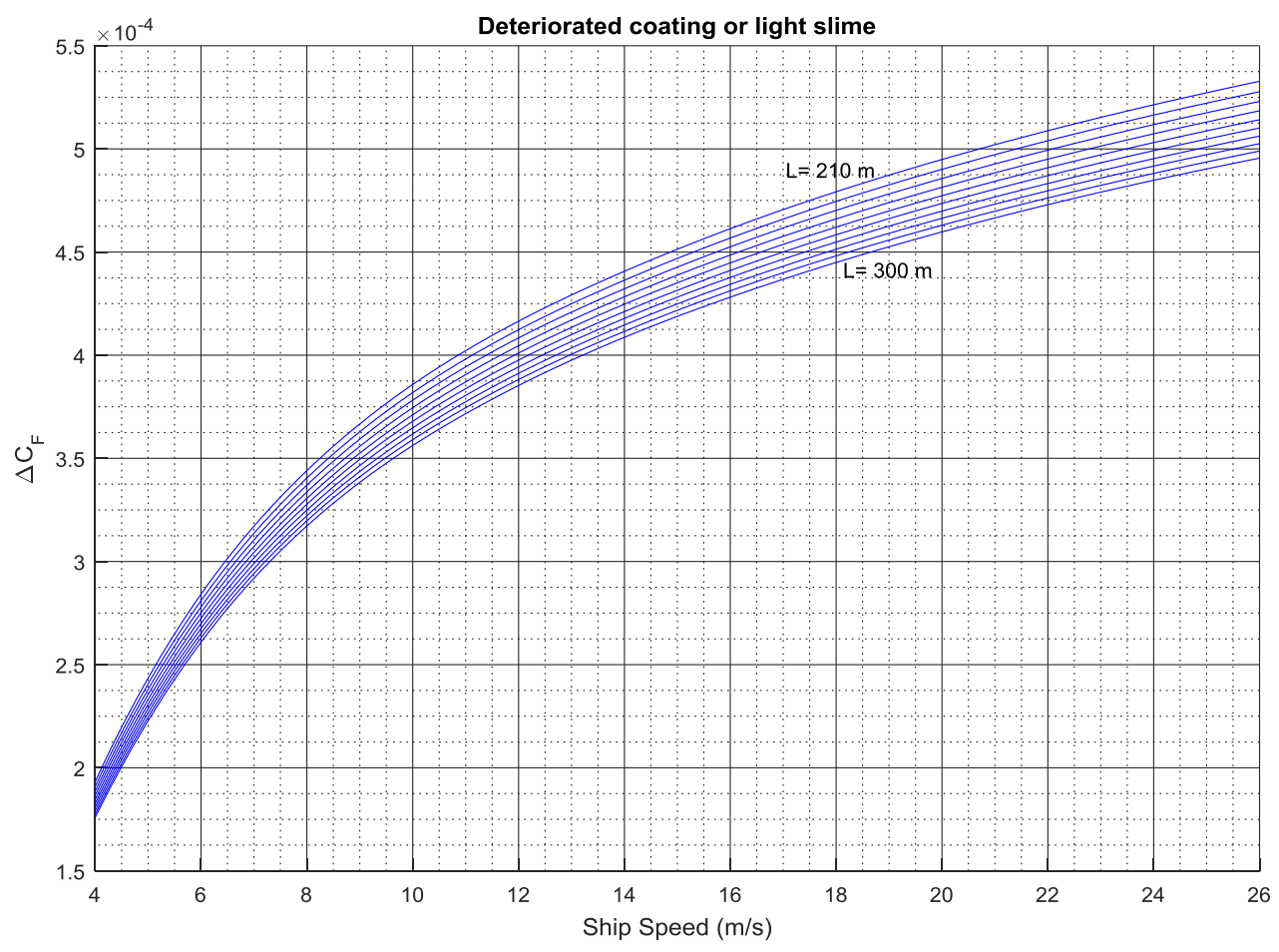

Figure A. 7 Added resistance diagram for ships with a deteriorated coating or light slime condition ( $\mathrm{L}=\mathbf{2 1 0}-\mathbf{3 0 0} \mathrm{m}, \mathbf{1 0 \mathrm { m }}$ increments)

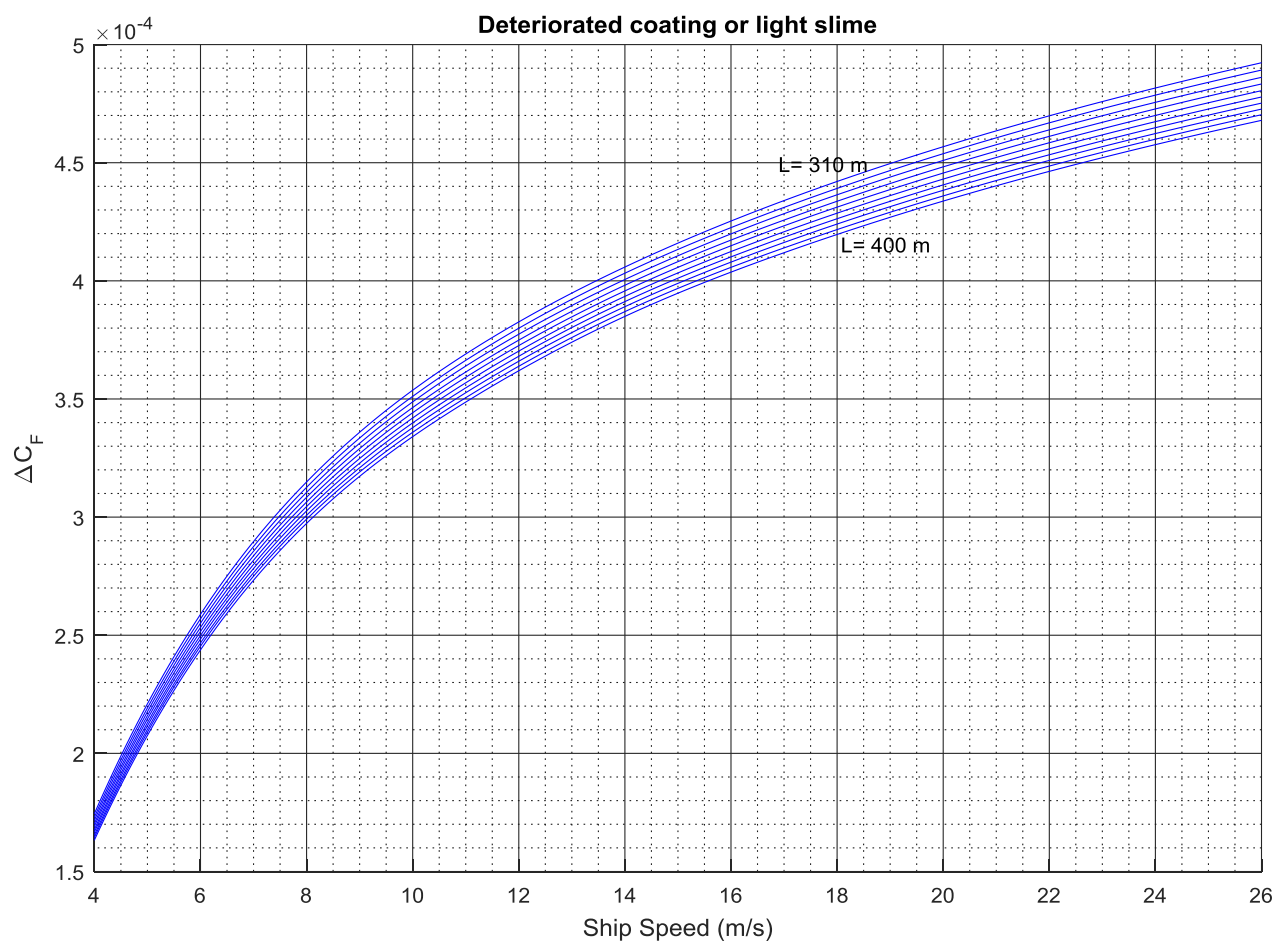

Figure A. 8 Added resistance diagram for ships with a deteriorated coating or light slime condition ( $\mathrm{L}=\mathbf{3 1 0}-\mathbf{4 0 0 \mathrm { m }}, \mathbf{1 0 \mathrm { m }}$ increments) 


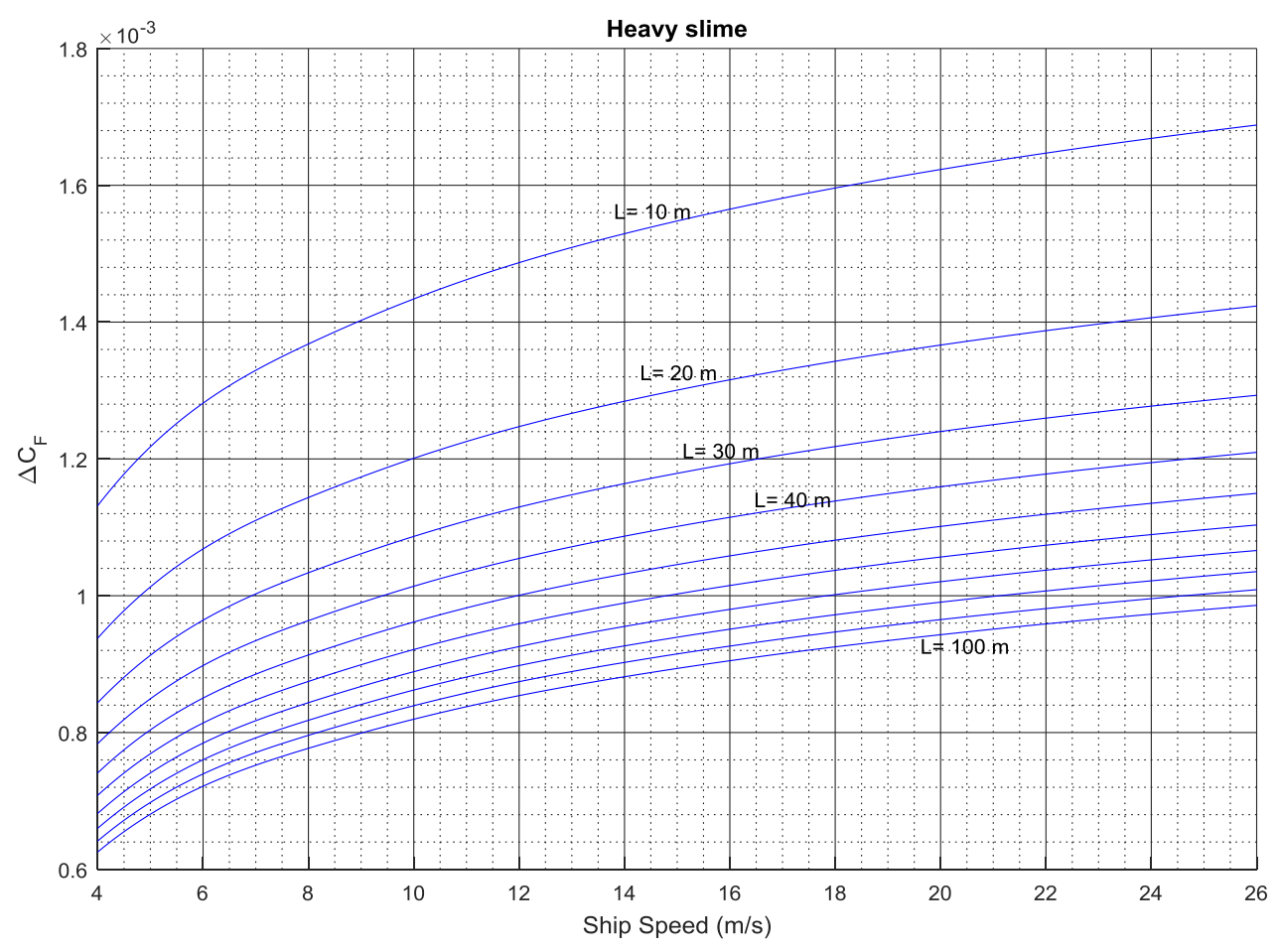

Figure A. 9 Added resistance diagram for ships with heavy slime condition $(\mathrm{L}=\mathbf{1 0}-100 \mathrm{~m}$, $10 \mathrm{~m}$ increments)

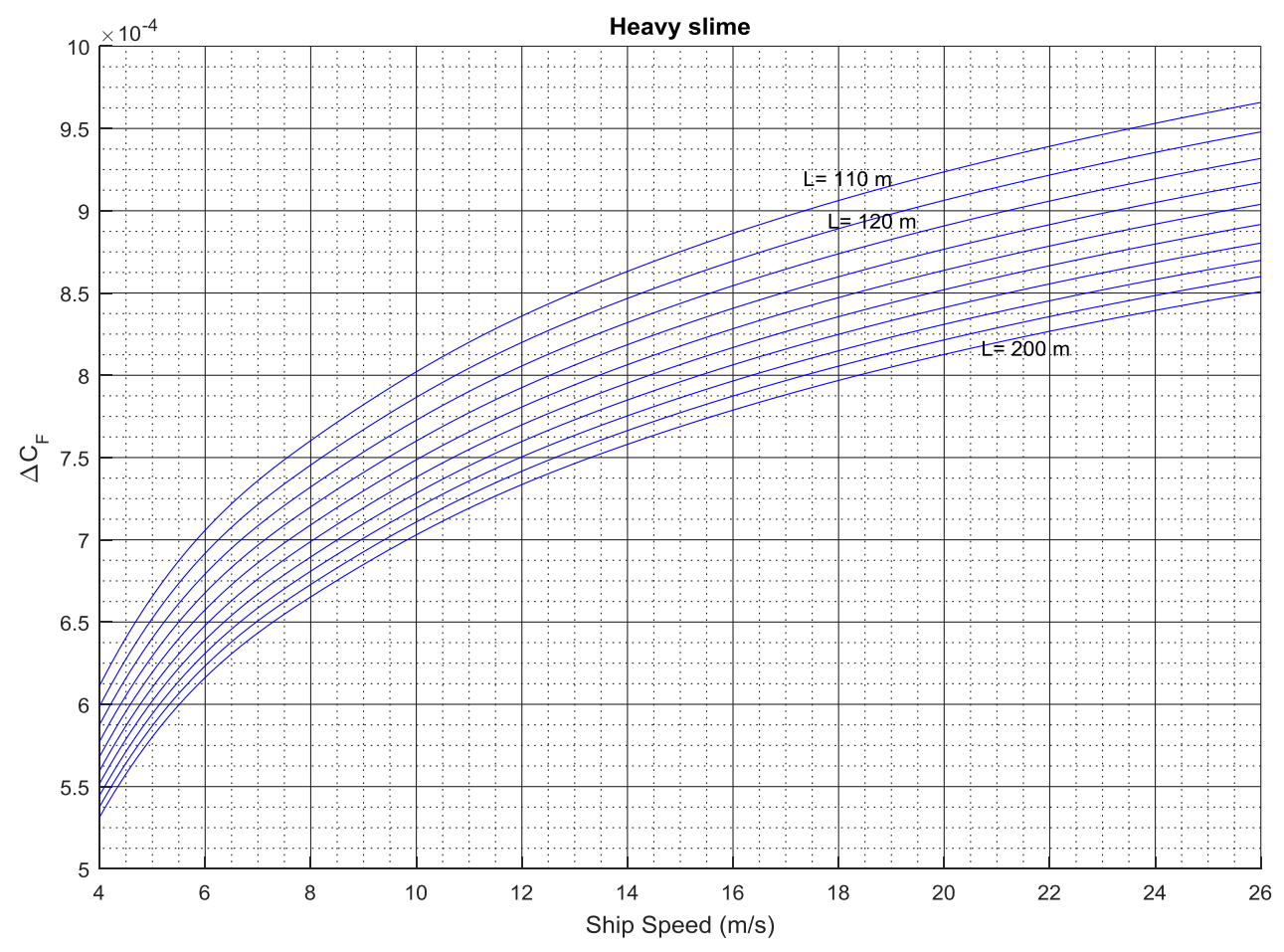

Figure A. 10 Added resistance diagram for ships with heavy slime condition $(L=110$ $200 \mathrm{~m}, 10 \mathrm{~m}$ increments) 


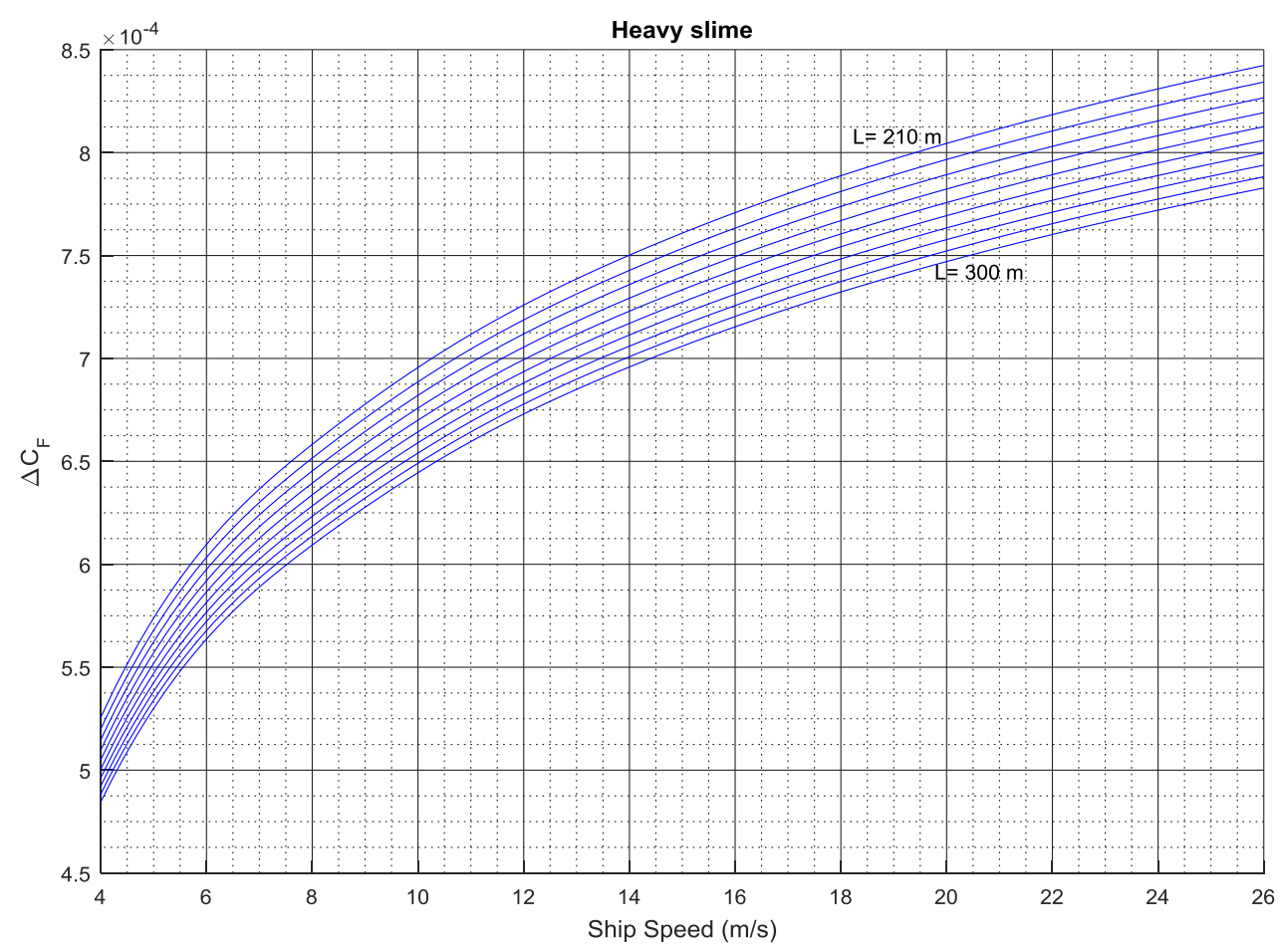

Figure A. 11 Added resistance diagram for ships with heavy slime condition $(L=210$ $300 \mathrm{~m}, 10 \mathrm{~m}$ increments)

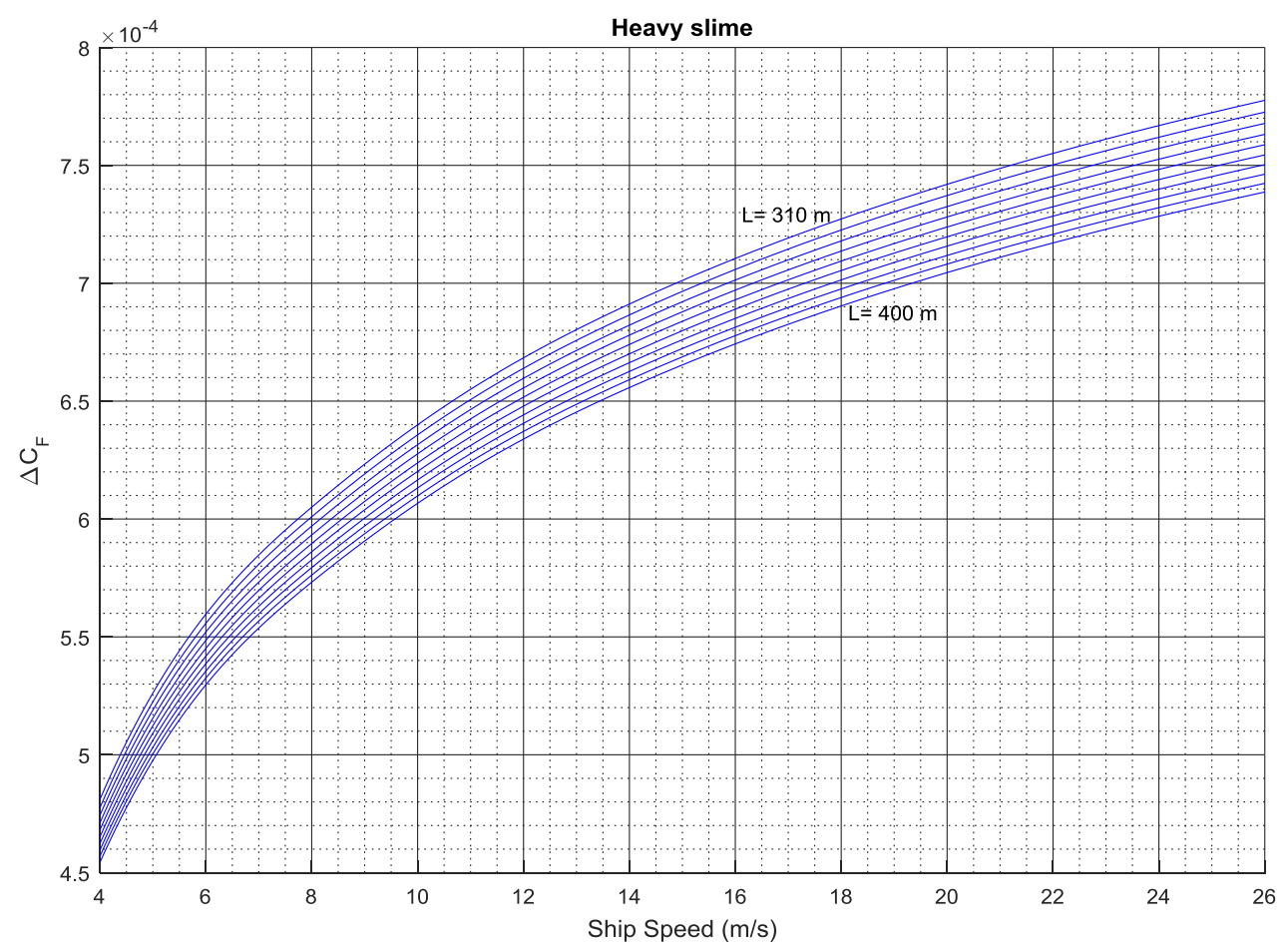

Figure A. 12 Added resistance diagram for ships with heavy slime condition ( $L=310$ $400 \mathrm{~m}, 10 \mathrm{~m}$ increments) 


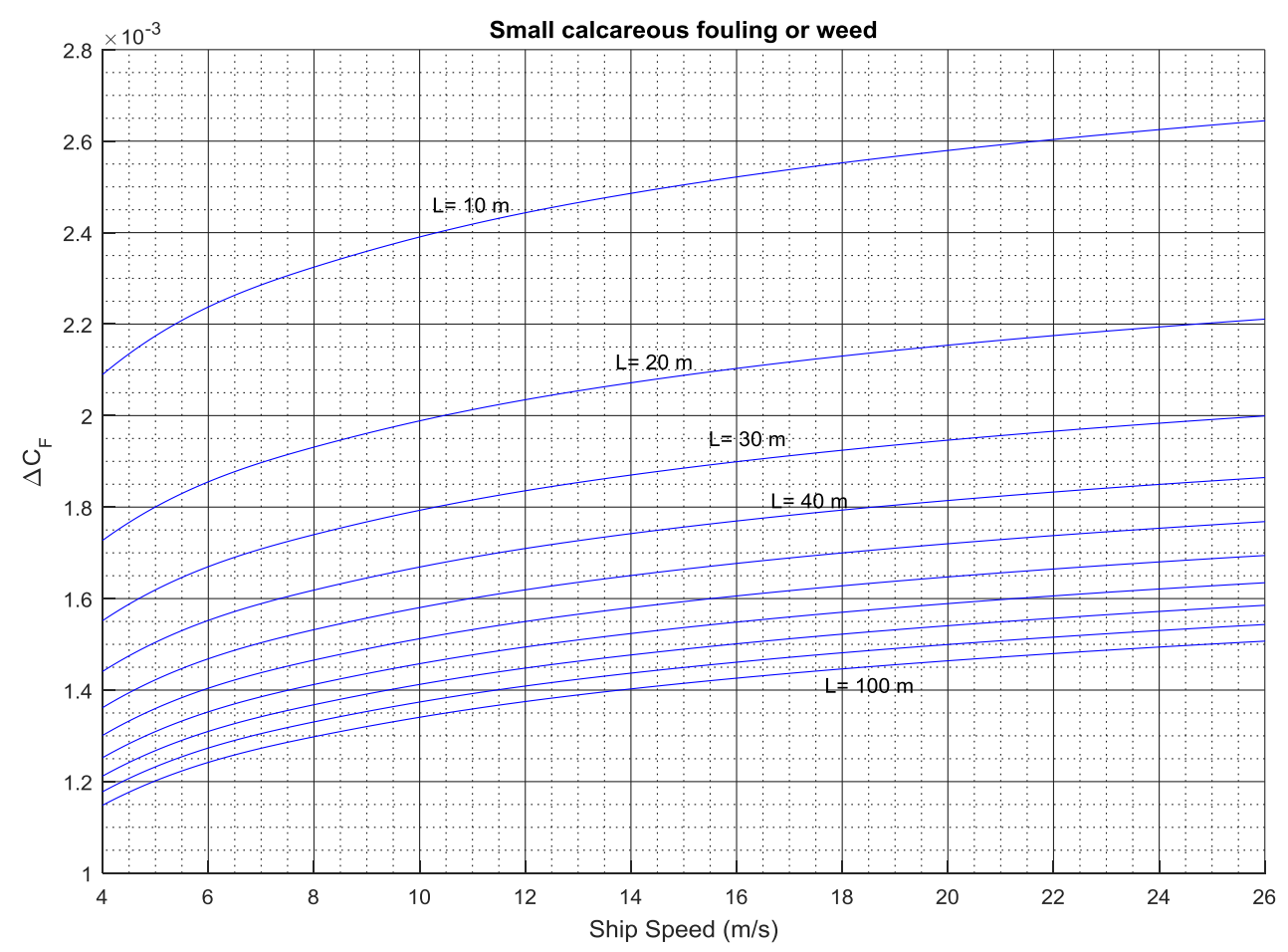

Figure A. 13 Added resistance diagram for ships with small calcareous fouling or weed ( $\mathrm{L}=10-100 \mathrm{~m}, 10 \mathrm{~m}$ increments)

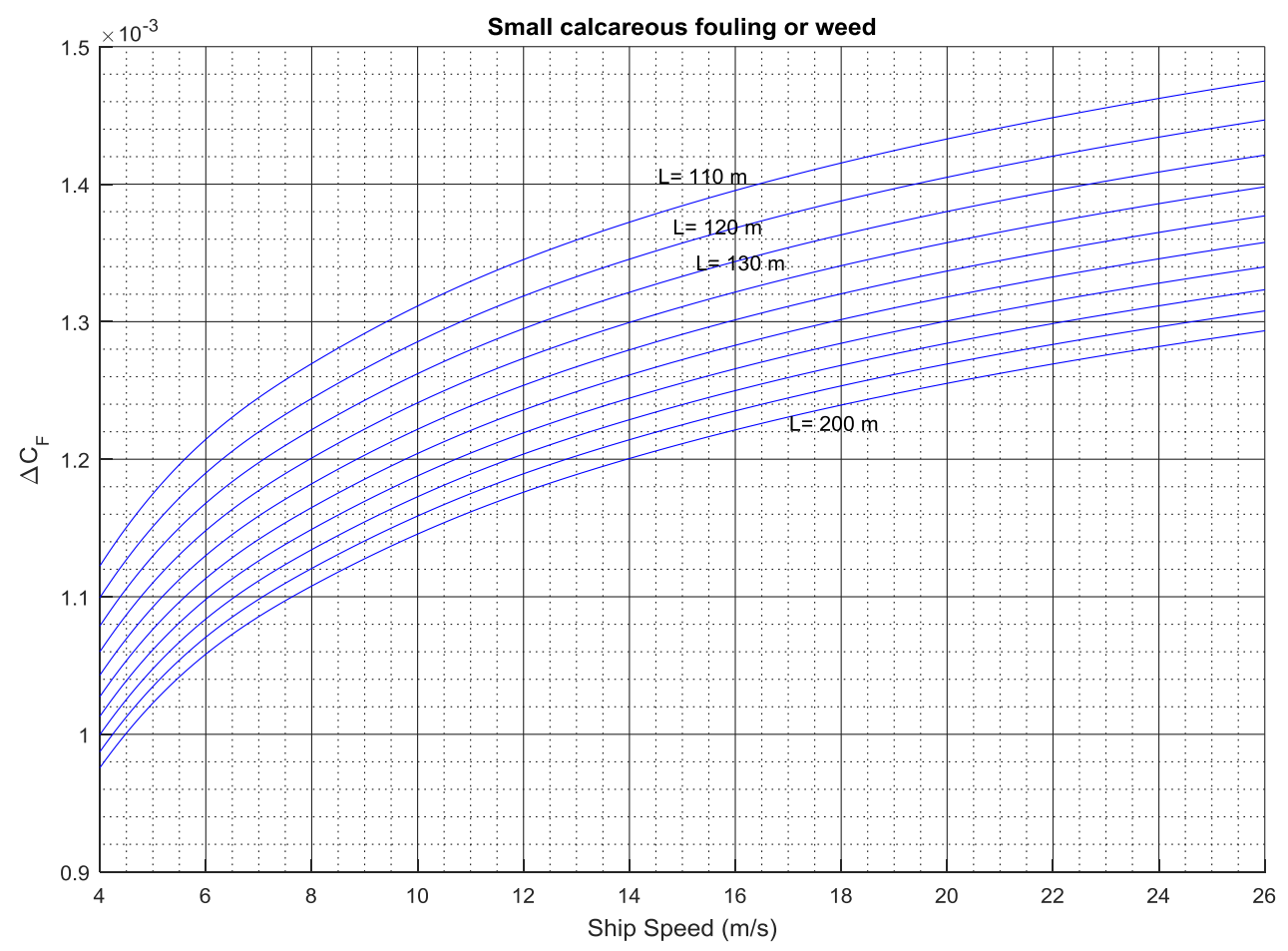

Figure A. 14 Added resistance diagram for ships with small calcareous fouling or weed ( $\mathrm{L}=110-200 \mathrm{~m}, 10 \mathrm{~m}$ increments) 


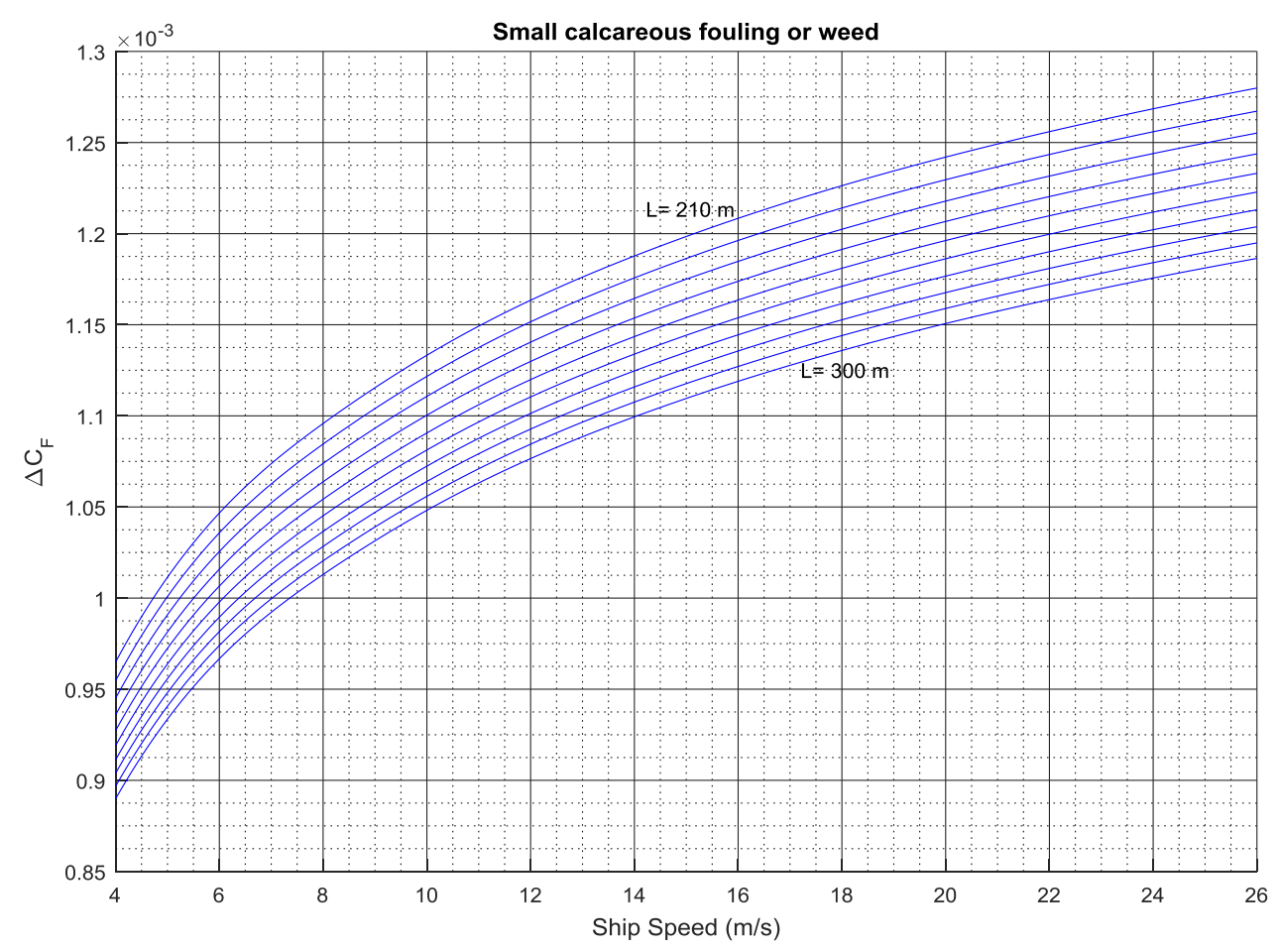

Figure A. 15 Added resistance diagram for ships with small calcareous fouling or weed

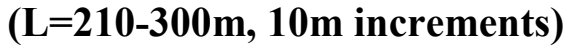

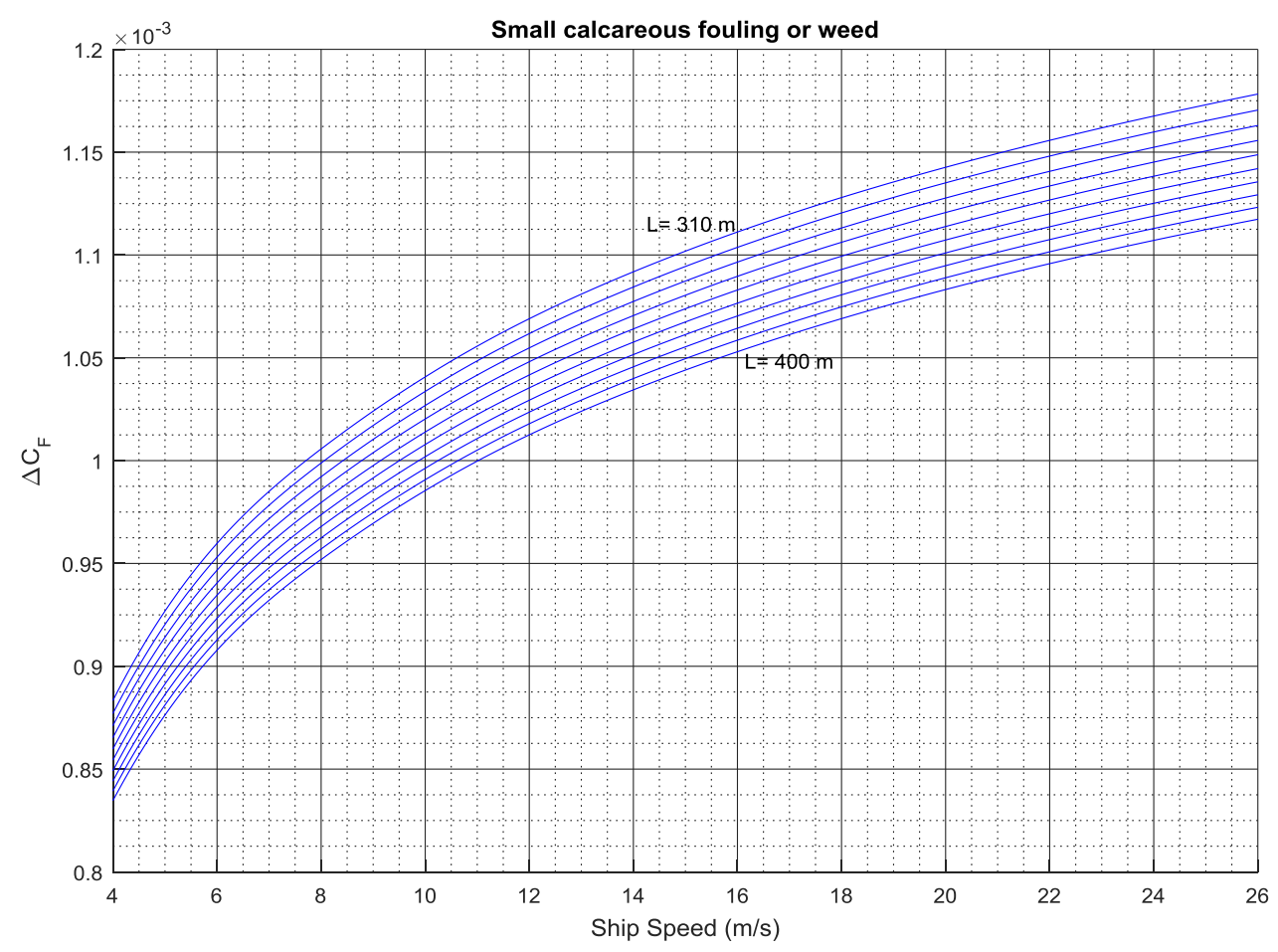

Figure A. 16 Added resistance diagram for ships with small calcareous fouling or weed ( $\mathrm{L}=310-400 \mathrm{~m}, 10 \mathrm{~m}$ increments) 


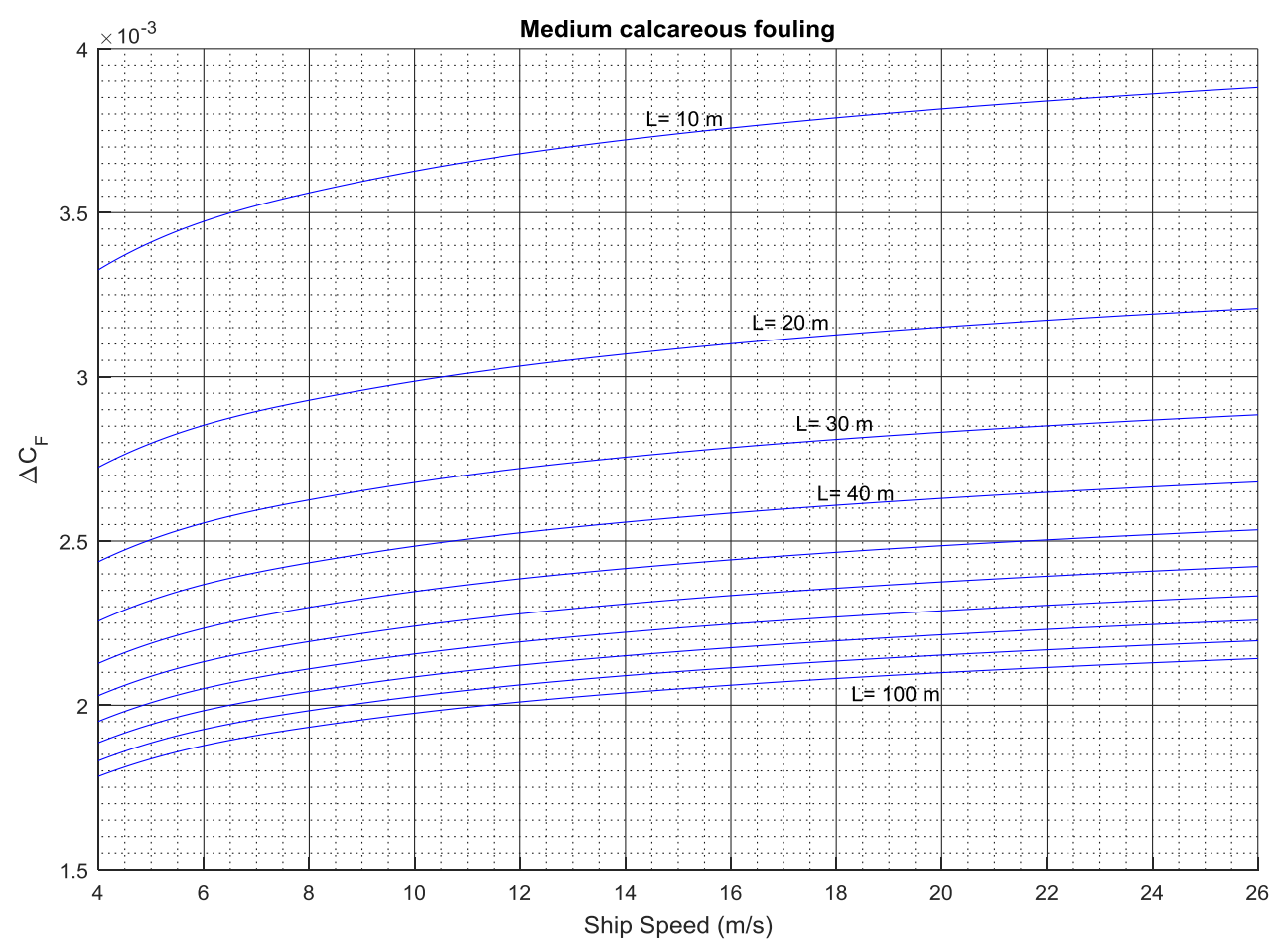

Figure A. 17 Added resistance diagram for ships with medium calcareous fouling ( $L=10-100 \mathrm{~m}, 10 \mathrm{~m}$ increments)

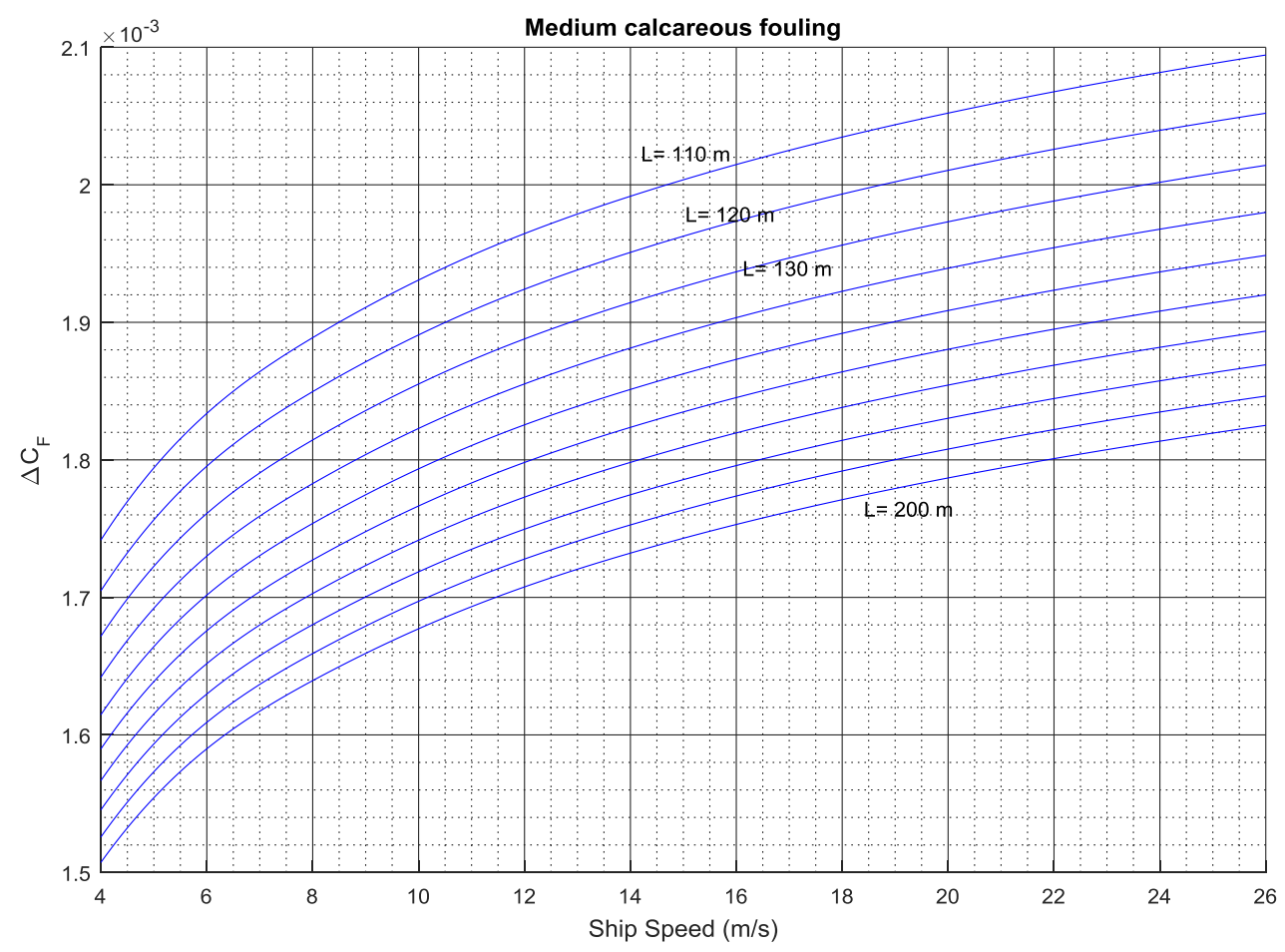

Figure A. 18 Added resistance diagram for ships with medium calcareous fouling or weed $(\mathrm{L}=110-200 \mathrm{~m}, 10 \mathrm{~m}$ increments) 


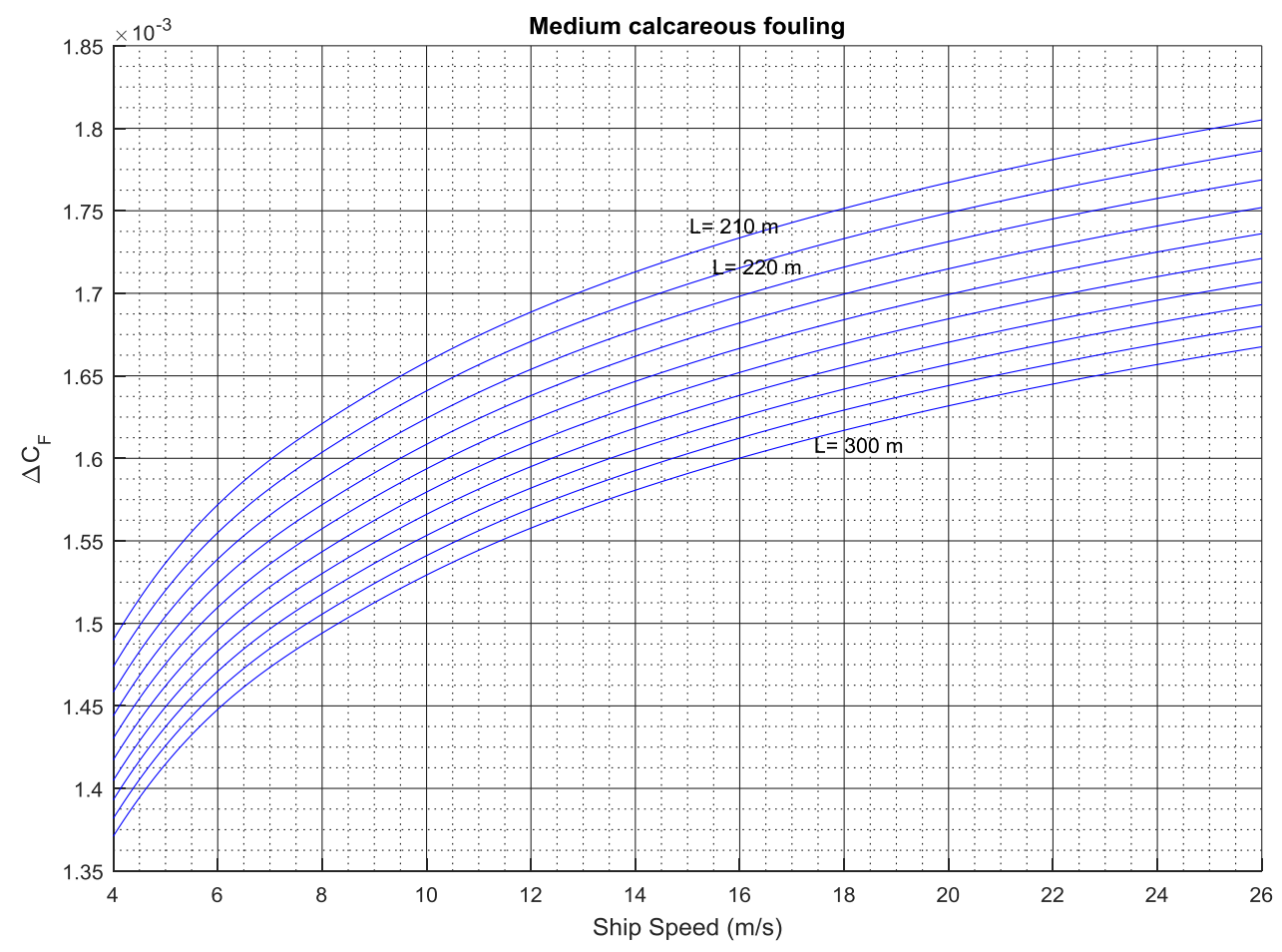

Figure A. 19 Added resistance diagram for ships with medium calcareous fouling or weed ( $L=210-300 \mathrm{~m}, 10 \mathrm{~m}$ increments)

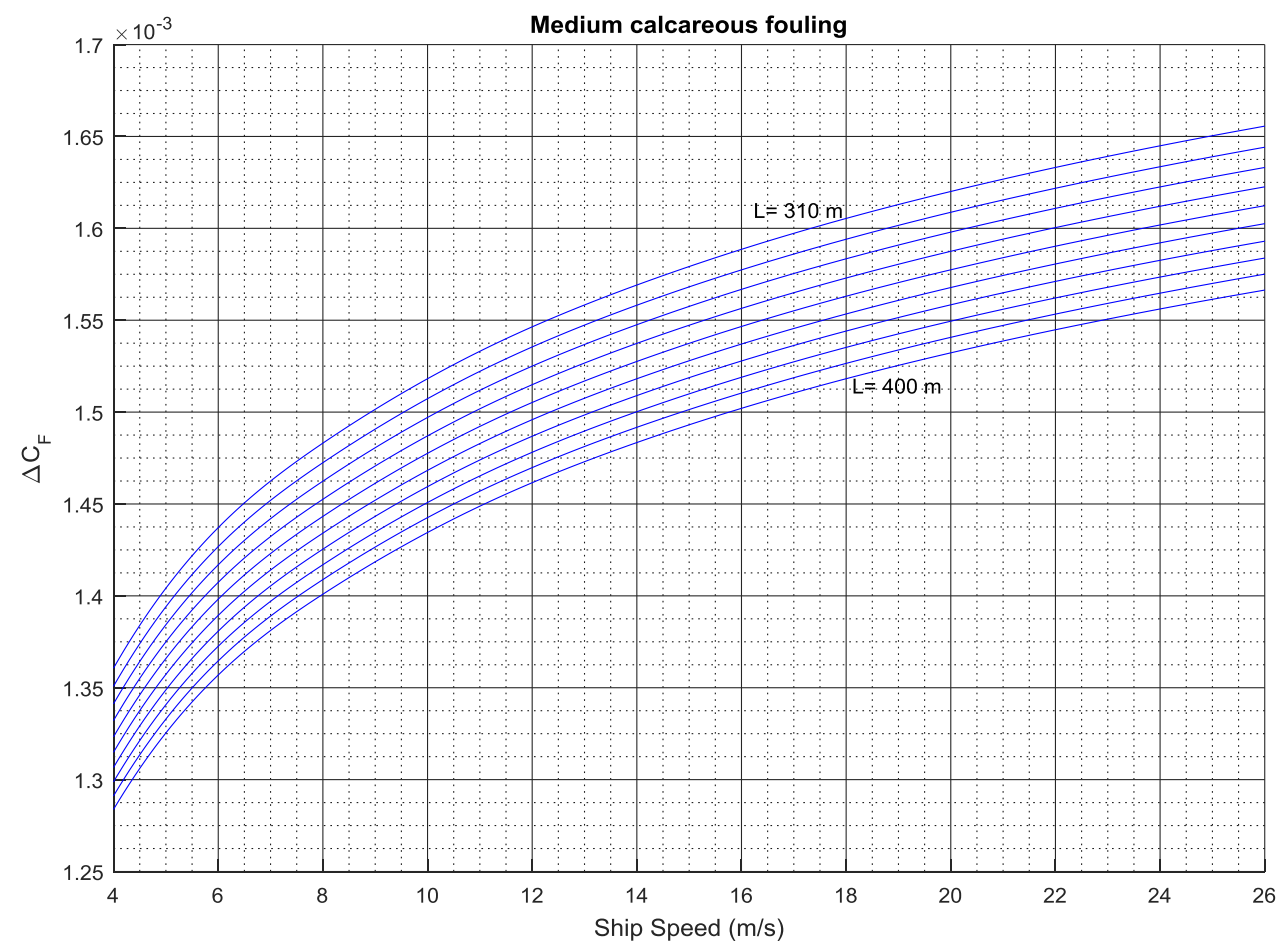

Figure A. 20 Added resistance diagram for ships with medium calcareous fouling or weed $(\mathrm{L}=310-400 \mathrm{~m}, 10 \mathrm{~m}$ increments) 


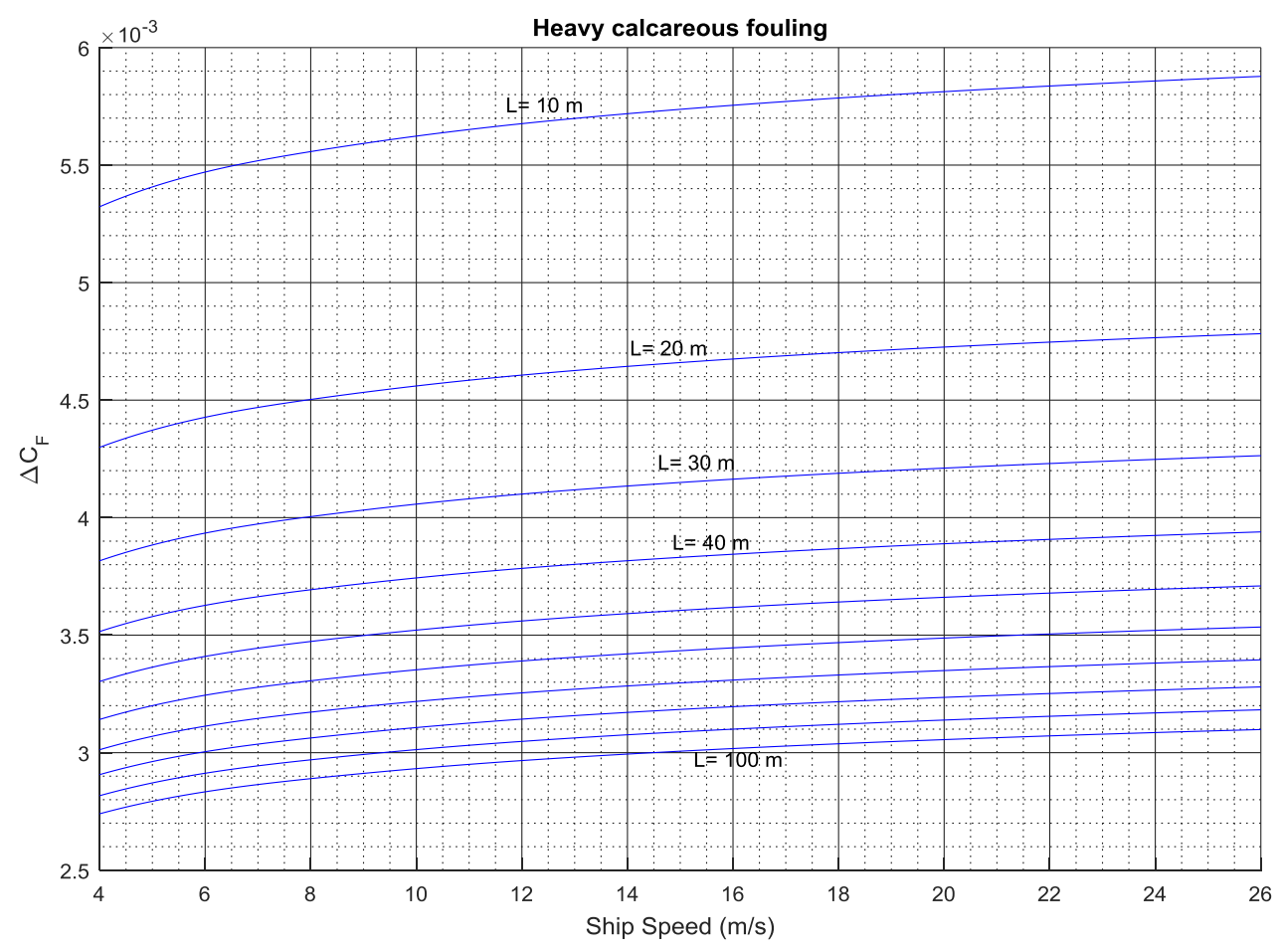

Figure A. 21 Added resistance diagram for ships with heavy calcareous fouling $(\mathrm{L}=10$ $100 \mathrm{~m}, 10 \mathrm{~m}$ increments)

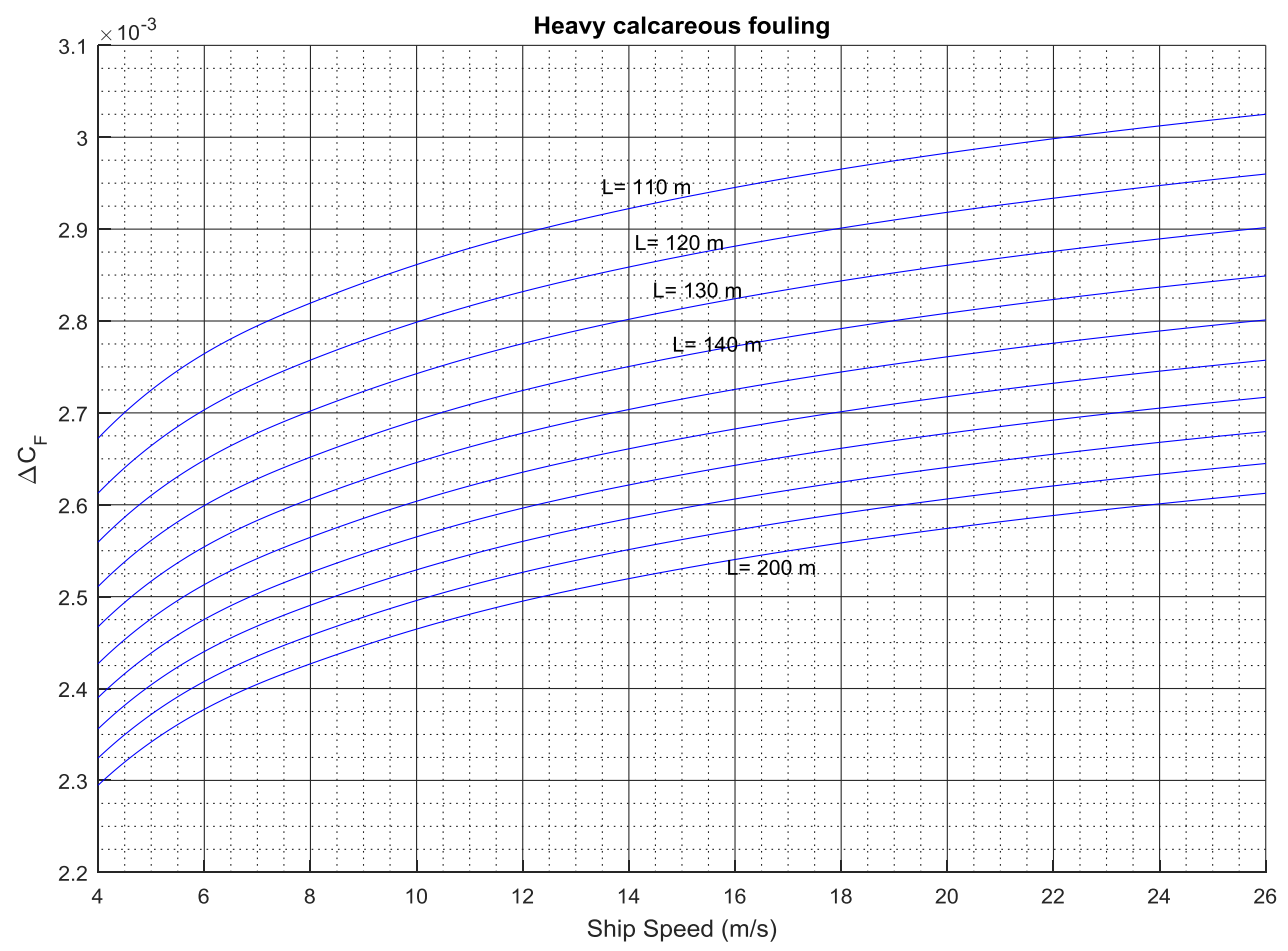

Figure A. 22 Added resistance diagram for ships with heavy calcareous fouling ( $\mathrm{L}=110$ $200 \mathrm{~m}, 10 \mathrm{~m}$ increments) 


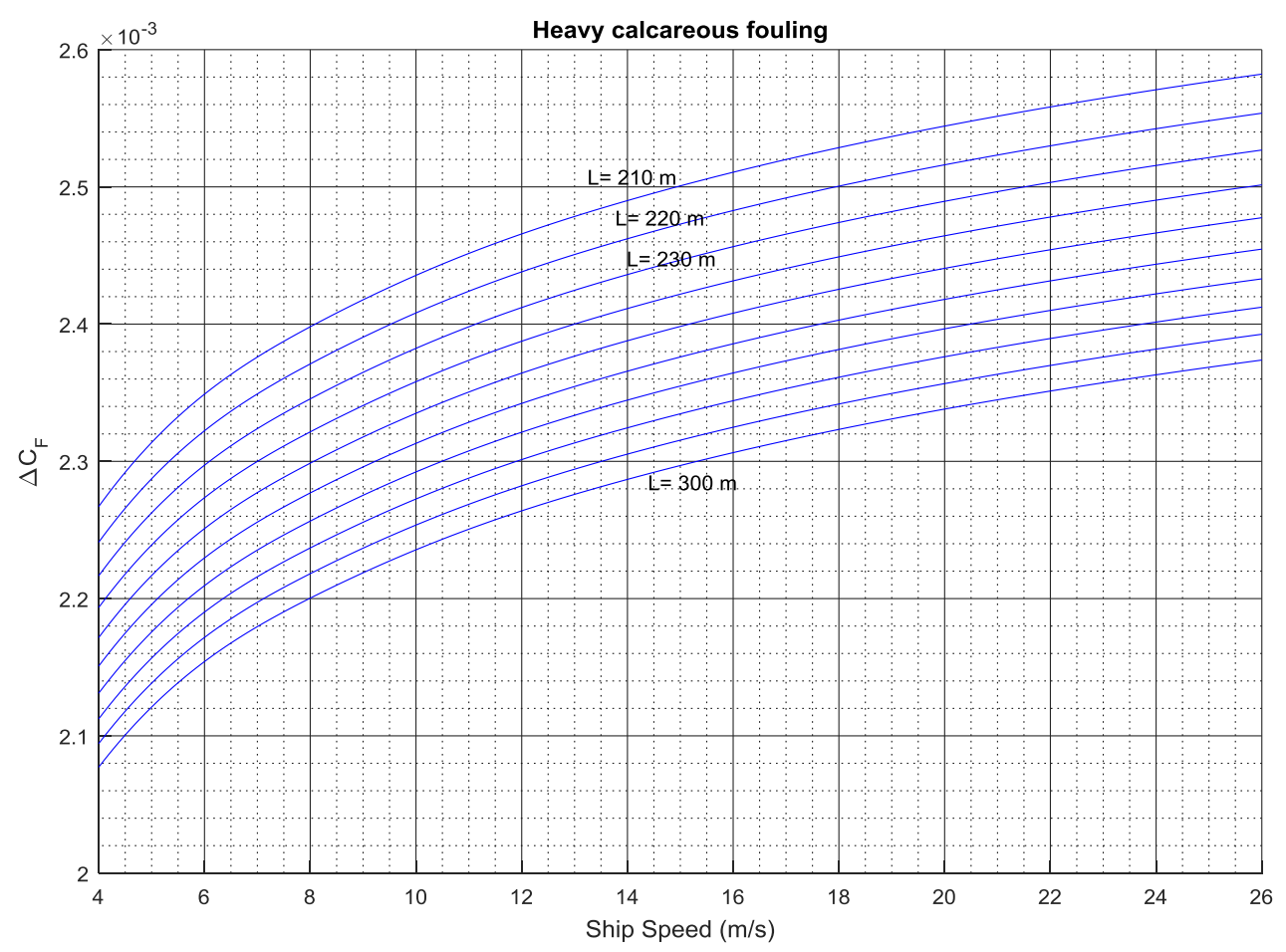

Figure A. 23 Added resistance diagram for ships with heavy calcareous fouling ( $\mathrm{L}=\mathbf{2 1 0}$ $300 \mathrm{~m}, 10 \mathrm{~m}$ increments)

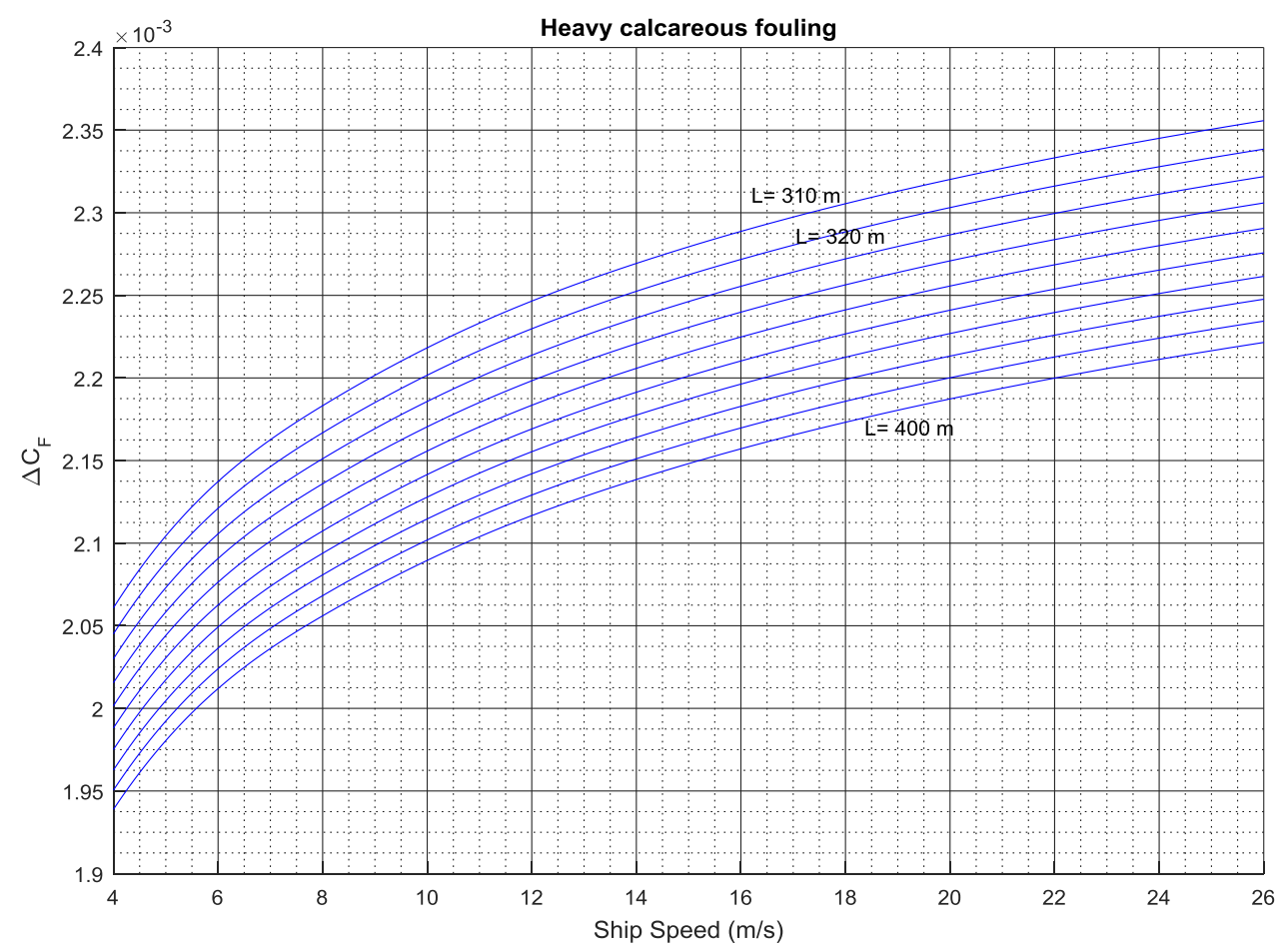

Figure A. 24 Added resistance diagram for ships with heavy calcareous fouling ( $\mathrm{L}=\mathbf{3 1 0}$ $400 \mathrm{~m}, 10 \mathrm{~m}$ increments) 